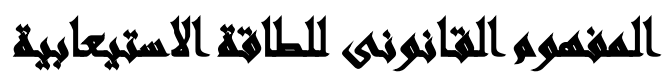

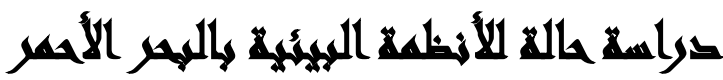

$[r \cdot]$

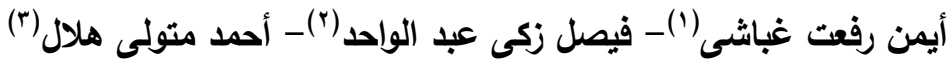

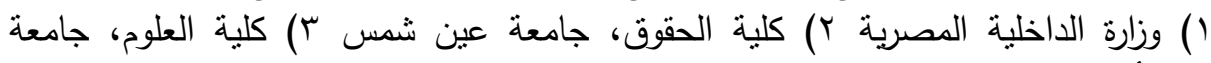

الأزهر

\section{المستخلت}

تهدف الدراسة الي التعرف على التشريعات والضوابط الإدارية المختصة بحماية البيئة

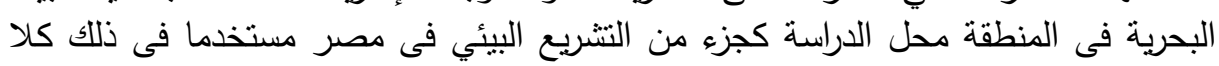

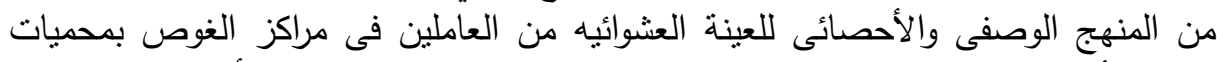

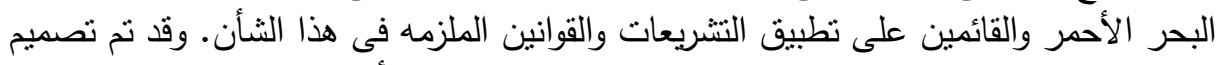

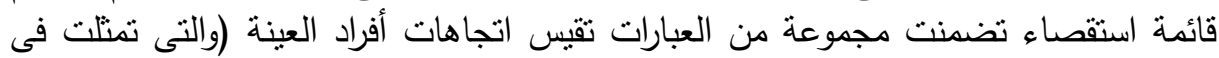

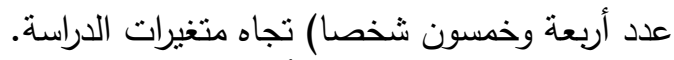

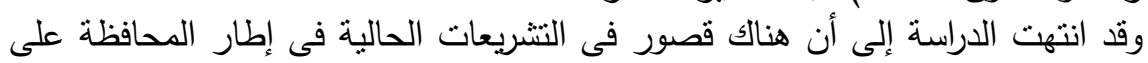

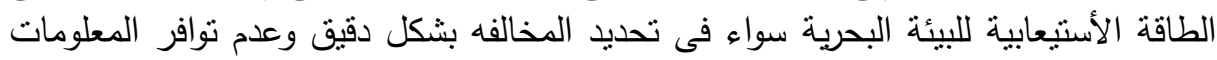

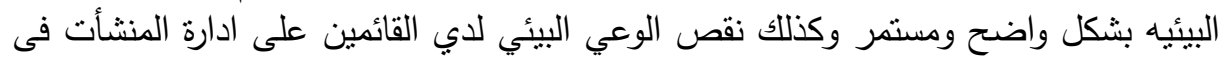

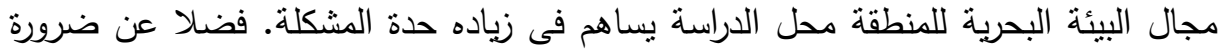
توافر شبكات رصد متطوره للرصد البيئي وبنك متكامل للمعلومات البيئيه يوفر لمتخذ القيات القرار

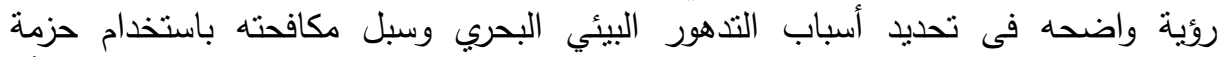
التشريعات القابلة للنتفيذ وبمسانده من جميع الأطراف المشاركه سواء التهاء المجتمع المدني أو

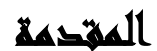

تأتى قضية الحفاظ على البيئة البحرية على قائمة أولويات الاهتمامات العالمية في القرن

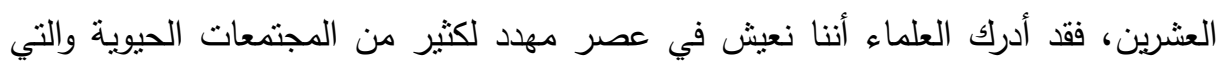

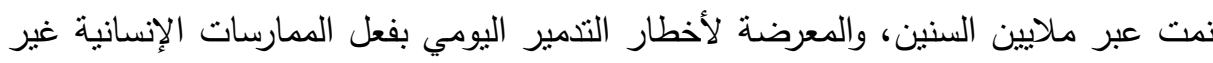
المدروسة، وقد دلت دراسات علماء الأحياء على أن أعداد الأنواع التي ستتعرض لألعار لأخطار

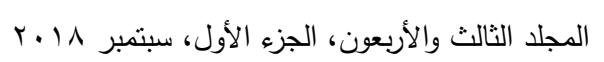


الانقراض خلال العقود المقبلة تقدر بالآلاف من الكائنات التي تعيش الآن إن لم يكن بعشرات

ومن هنا سعى كثير من العلماء إلى التفكير في أسلوب أمتل لاستخدام موارد البيئة

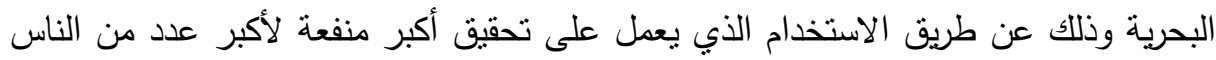

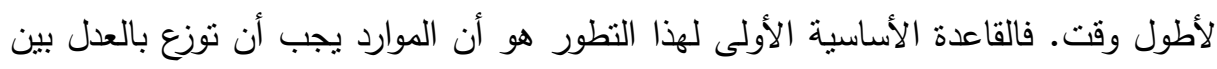

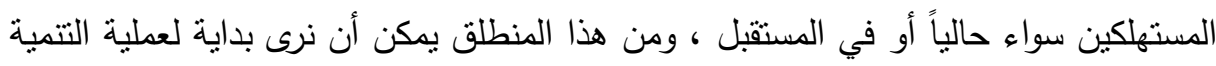
المستدامة (Sustainable Development) وهى تلك التتمية التي تستجيب لإثباع حاجات

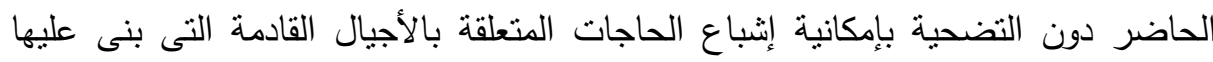

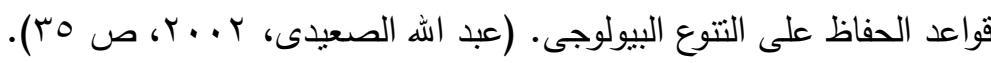

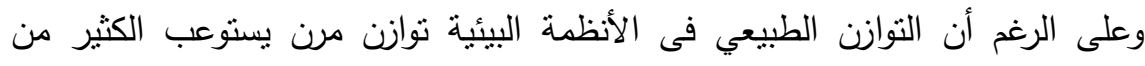

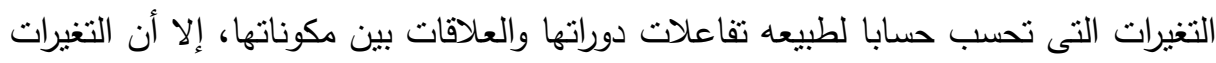
المخلة الناجمة عن الأنشطة البشرية غير المستدامة للمورد يحد قدرتها الأستيعابية، ذلك أنه

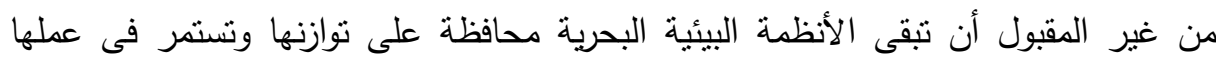

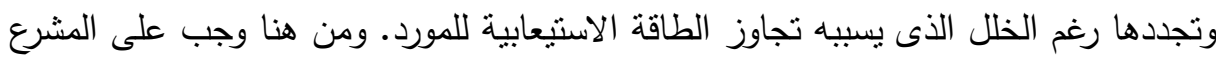
عند وضع حدود للطاقة الأستيعابية للموارد الطبيعية أن يسن فيها من التشريعات مايكفل عدم التهابه

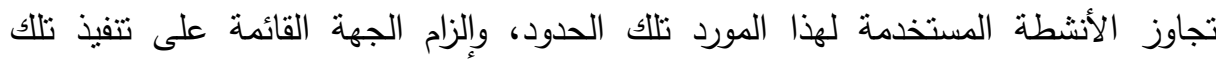

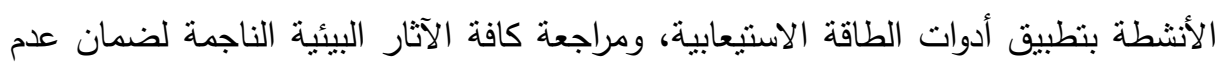
تدهور تلأك الأنظمة البيئية. ومن هنا يأني مصطلح الطاقة الاستيعابية بانتثاره الواسع فى عمليات التتمية المستدامة،

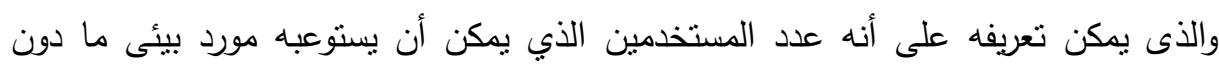

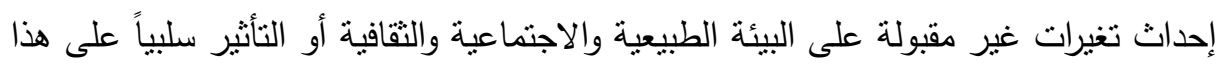

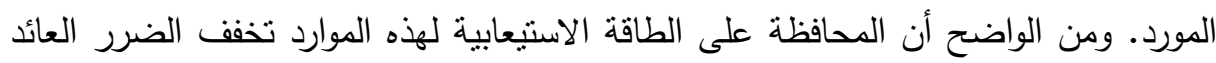

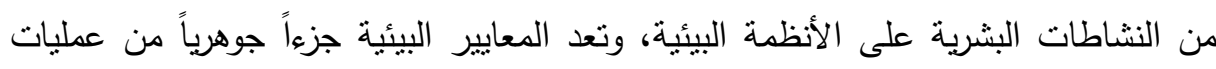

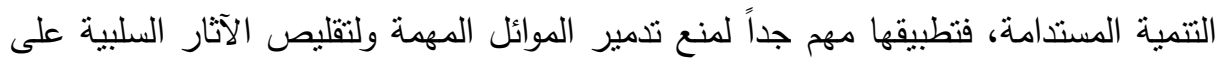

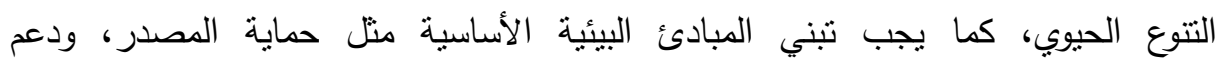


المجتمعات المحلية، ودعم الحماية وغيرها حيث يمكن تضمينها في معظم الآليات

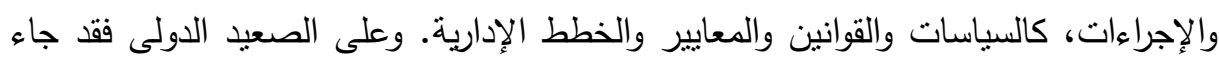

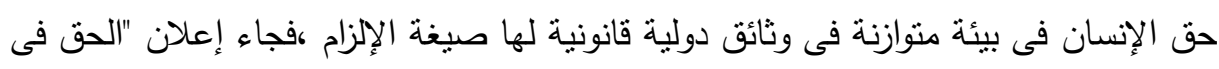

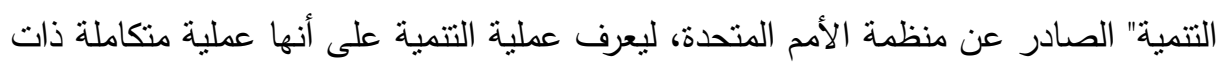

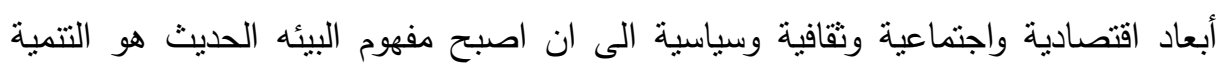
المستدامة ذات الأبعاد المتعددة، التى تقوم على الحفاظ على البيئة واحترام الطاقة الاسنيعابية

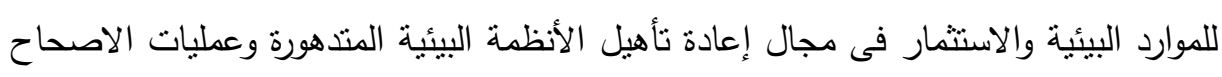
وتحقيق المساواة الاقتصادية والاجتماعية بين الأفراد، وزيادة وعى الأفراد بحقوقهم البيئية وطرق المطالبة بها.

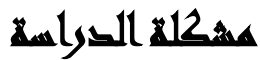

تشير البيانات والأحصائيات الدولية ) People and Reefs People and Reefs Successes and Challenges in the Management of Coral Reef Marine Protected Areas UNEP Regional Seas Report and Studies No. 176 2004) كما أثنارت دراسة كل من ريتشارد بريماك، صفاء محمد إسماعيل ومحسن رشاد طه

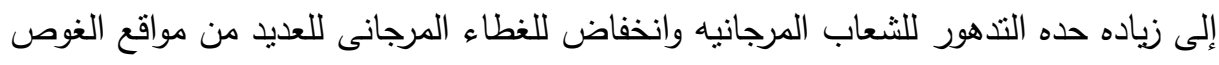

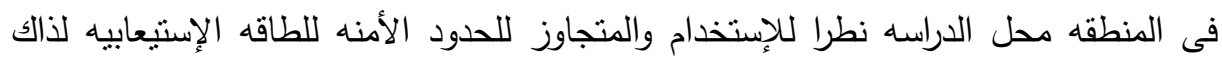
المورد والذي يعد من أهم مصادر الدخل القومي فى صناعه السياحه المصريه إذا ما تم الإدارة بشكل مستدام.

\section{أسئله المهيه}

1-ما إمكانيه تفعيل التشريعات والقوانين ذات الصله بالمحافظه على الطاقه الإسنيعابيه للبيئة

$$
\text { البحريه وبأي درجة؟ مانه }
$$

ץ-ما مدى الإستعانة بالمجتمع المدنى من خلال المنظمات غير حكومية فى إدارة منظومة

$$
\text { البيئه البحرية فى مصر؟ الإنعانه بالبئع }
$$

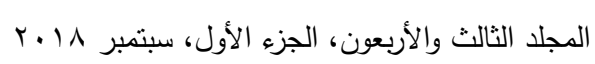




\section{هروض المهير}

ا. الفرض الأول (العدم): التشريعات والقوانين البيئيه ليس له تأثير جوهري للحد من

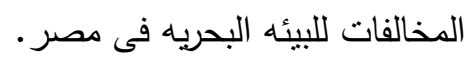

r. الفرض الثاني (البديل): تؤثز توافر والوعي البيئي لدي المستخدمين والقائمين على إداره

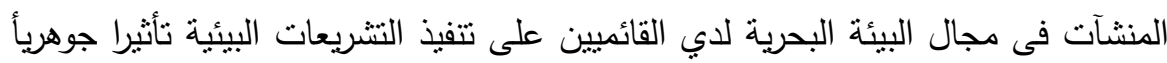

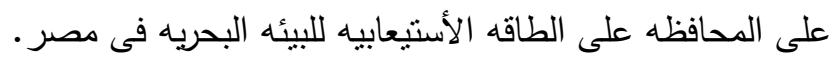

\section{أهمبر المههم}

ترجع أهمية الدراسة على الصعيدين الدولى والمحلى إلى عدة أسباب أهمها: 1-زيادة التهديدات غير المسبوقة للنظم البيئية البحرية. r-محاولة حصر بعض المخالفات البيئية ومعرفة أسبابها. r-محاولة الدراسة مسايرة الاهتمام العالمى والمحلى لقضايا الطاقة الاستيعابية بصفة عامة

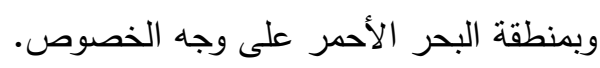
وتعد مصلحة الموانى والمنائر وهيئة قناة السويس وهيئات الهوصن الموانى بجمهورية مصر العربية والهيئة المصرية العامة لحماية شواطىء الهيئة المصرية العامة للبترول والهيئة العامة وهئه لتتمية السياحة والإدارة العامة لشرطة المسطحات والبيئة والقوات البحريه من أهم الجهات المستفيده من تلاك الدراسة.

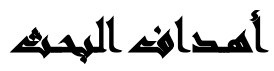

1-محاولة التعرف على بعض أنواع المخالفات البيئية ووسائل الضبط الإدارى المستخدمة فى حصر تلك المخالفات الناتجة عن النشاط البشرى فى منطقة الدراسة. r-دراسة أهم النتريعات والضوابط الإدارية المختصة بحماية البيئة البحرية فى المنطقة محل فلئل الدراسة كجزء من التشريع البيئي فى مصر .

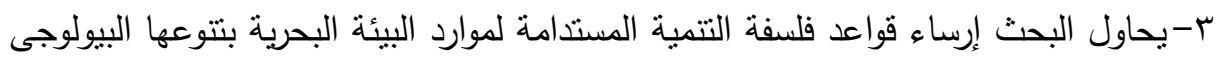
من خلال الاستخدام الرشيد لهذا التتوع. ع-تحاول الدراسة مساعدة المهتمين بقضايا التشريع البيئى فى رسم سياساتهم التشريعية 542

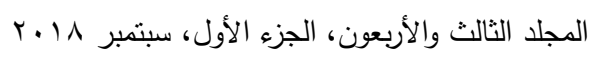


لحماية البيئة البحرية بتتوعها البيولوجى كأحد مبادئ التتمية المستدامة.

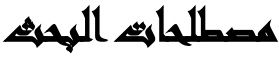

الطاقة الاستيعابية: عدد المستخدمين الذي يمكن أن يستوعبه مورد بيئى ما دون إحداث

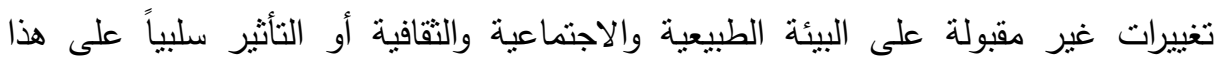

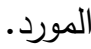

النظام الإيكولوجي: مصفوفة العلاقة التفاعلية التكاملية المتوازنة داخل أى وحدة بيئية

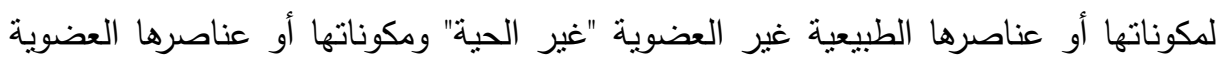
"الحية" وفق نظام غاية في الدقة والتوازن من خلال ديناميكية ذاتية تحكمها النواميس الكونية الإلهية التي تضبط حركتها وتفاعلها في إيقاع متتاسق يعطي النظام القدرة على إعالة الحياة

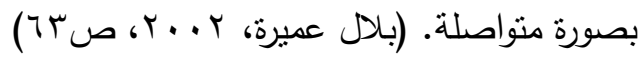
البيئة البحرية: مسطحات من الماء المالح المتصلة ببعضها اتصالاً حراً طبيعياً، وقاعها وباطن تربتها، وبما تحتويه من كائنات جية حيوانية ونباتية، وثروات طبيعية تشكل فى مجملها عناصر الحياة البحرية، وباعتبارها نظاماً بيئياً متكاملاً. التنمية المستدامة (Sustainable Development): وهى تلك التتمية التي تستجيب لإثباع حاجات الحاضر دون التضحية بإمكانية إثباع الحاجات المتعلقة بالأجيال القادمة

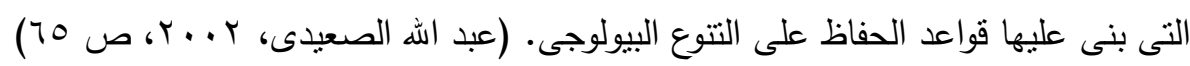

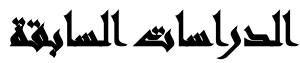

تعددت الدراسات التى تتاولت موضوع البيئة البحرية وكذللك التتوع البيولوجى سواء على ألى التهاء

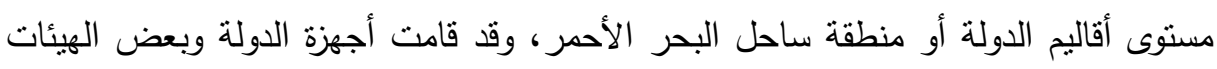
البحثية والثركات ببعض الدراسات حول منطقة ساحل البحر الأحمر خدمة لأهداف التتمية 
دراسة صفاء محمد إسماعيل( 9 و (1) ): فى مدى فاعلية التثريعات البيئية فى جمهورية مصر العربية للحفاظ على التتوع البيولوجى، رسالة ماجستير ، معهد الدراسات والبحوث البئية البئة، جامعة عين شمس ، القاهرة.

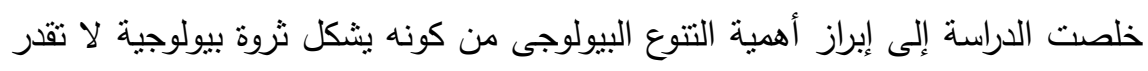

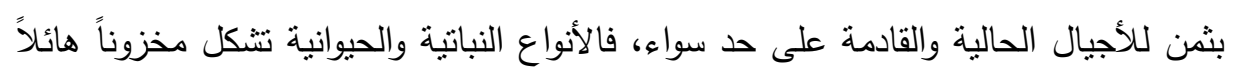
يعمل على تزويد الإنسان بالعديد من احتياجاته الأساسية. دراسة محسن رشاد طه( 99 (9 1) ): إدارة عمليات التنمية السياحية بالبحر الأحمر ، رسالة

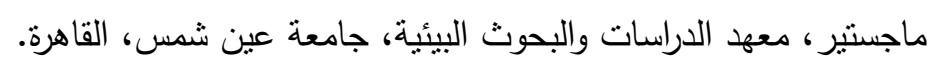

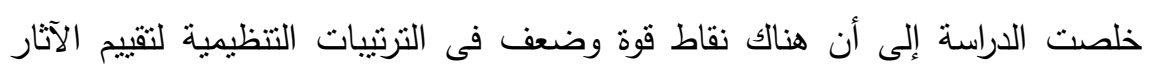

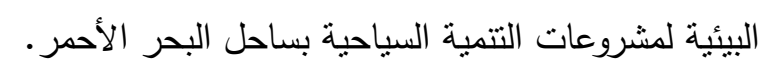

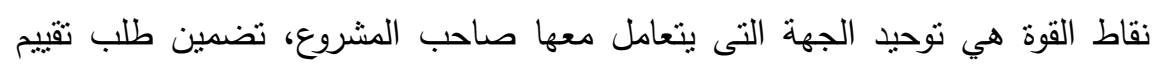

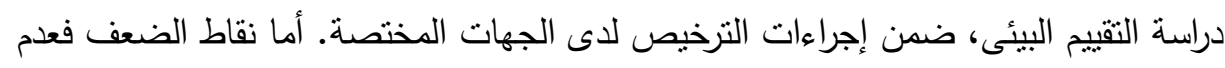

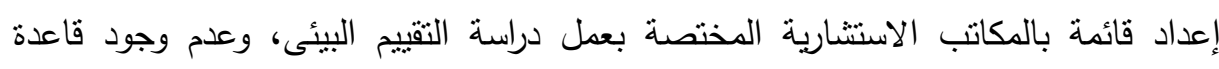

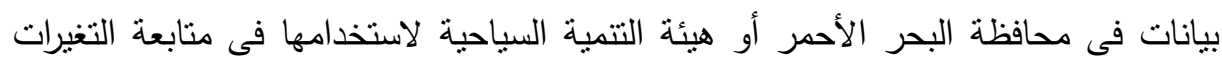

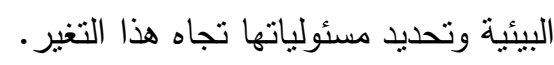
كما عرضت عدد من التعريفات فى وثيقة قانونية بغرض إعطاء معنى خاص متفق عليه

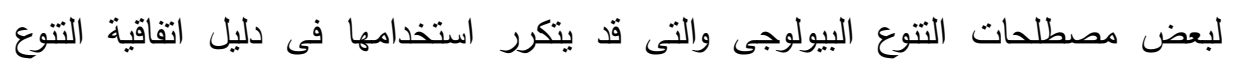
البيولوجى.

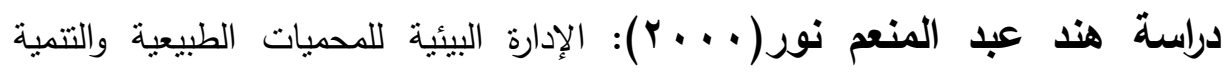

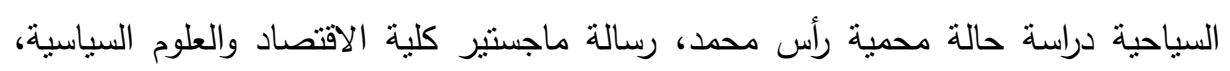
جامعة القاهرة.

خلصت الدراسة إلى وجود عديد من المشكلات التى تواجه الدحميات الطبيعية فى مصر

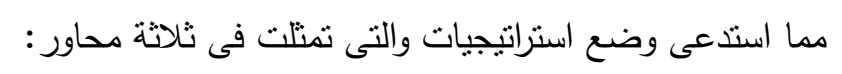

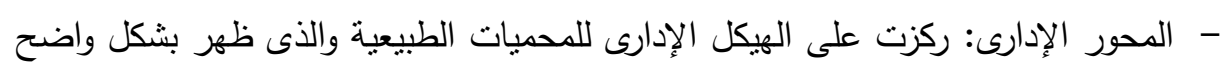

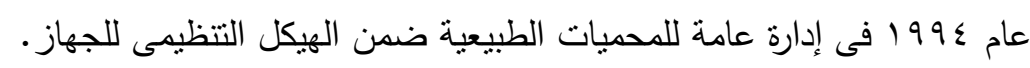
544

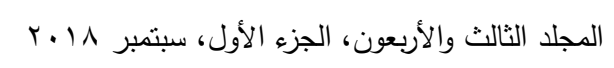




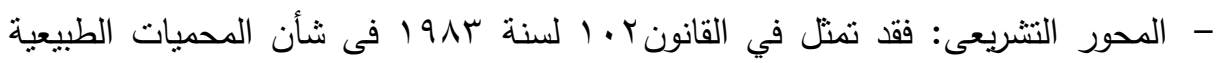
وقانون البيئة رقم ع لسنة ـ99 1 1 والاتفاقيات والقوانين الدولية والإقليمية والمحلية والقرارات الوزارية المتعلقة بالمحميات الطبيعية. - وتمتل المحور الثالث فى الخطة القومية للعمل البيئى فى مصر والتى مثلت إدارة المحميات الطبيعية أحد أولوياتها.

ورغم وجود تلك المحاور إلا أن المحميات فى مصر مازالت بحاجة إلى استكمال الدراسات العلمية التى يمكن أن تساعد على إدارتها إدارة بيئية قابلة للاستمرار .

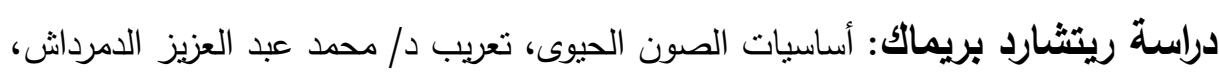

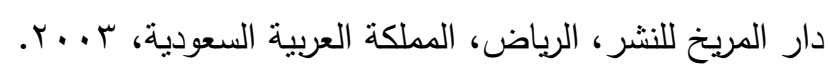

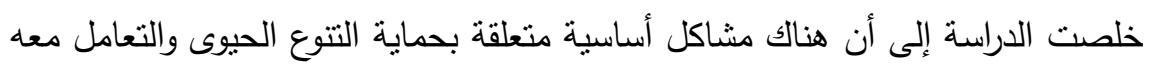

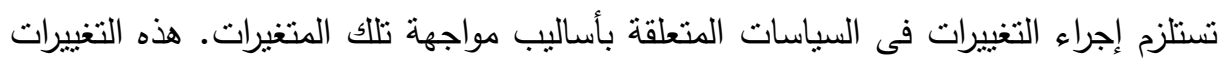

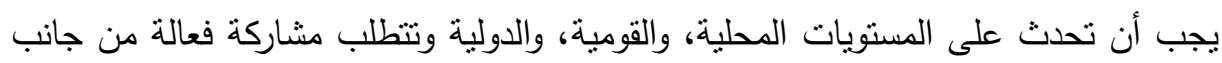
الأفراد والمنظمات البيئية والحكومات. التعليق على الدراسات السابقة: لم تتطرق أحد من الدراسات السابقة كما نما الى علم الباحث إلى أهمية إدارة أنظمة البيئة البحريه فى مصر وفقا لدفهوم الطاقة الأسنيعابية ومردودها على التتميه المستدامة.

\section{الإطالر المعرخهيه}

المنهج التحليلى: وتبرز أهمية هذا المنهج فى تتاول المعطيات والظواهر والبيانات المختلفة بالتحليل من كافة جوانبها، لربط واستخلاص ما قد يكون من علاقات قد تكثيف عن حقائق

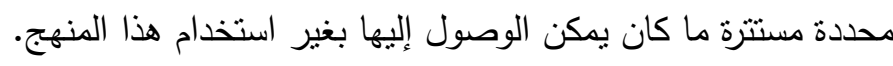
المنهج الوصفى: لشرح الوقائع والأحداث المختلفة بهدف إعطاء صورة واضحة عن ماهية

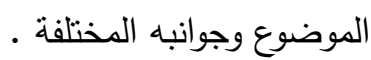
كما تم الاستعانة بالأسلوب الأحصائي للتأكد من صحه فروض الته الدراسة.

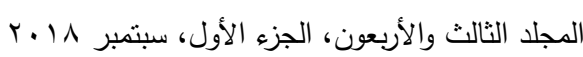




\section{مشورت المهند}

الحد المكاني: الأنظمة البيئية بالبحر الأحمر الأراضى الرطبة (Wetlands)، واللاجونات،

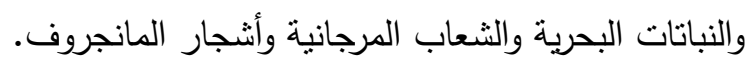
الحد الزمنى: وهي الفتره اللازمه للاراسة الحقلية والتى استمرت لمده عام من يناير 10 • بام حتى يناير 17 • بام.

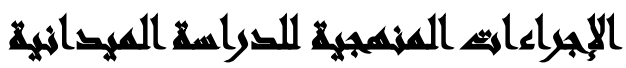

عينة الاراسة: نم اختيار عينة عشوائيه (·؟) من القائمين على تطبيق التشريعات والقوانين الملزمه فى هذا الثأن وطرح الأسئلة السالفة الذكر عليهم ومناقتشتهم فى كل سؤال منهم. تم اختيار عينة عشوائية (؟ شخص) من العاملين فى مراكز الغوص بمحميات البحر

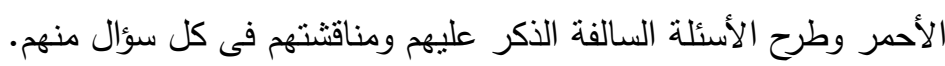

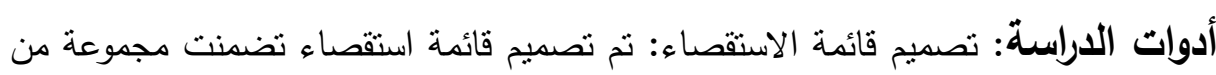
العبارات تقيس اتجاهات أفراد العينة تجاه متغيرات الدراسة، ولتصميم هذه القائمة، فقد قام التهاء الباحث بالاطلاع على عديد من الدراسات السابقة فى مجال موضوع الدراسة.

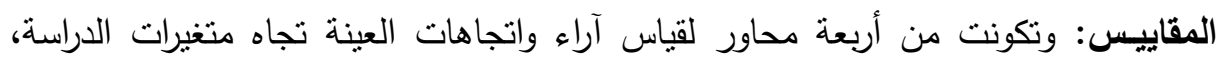

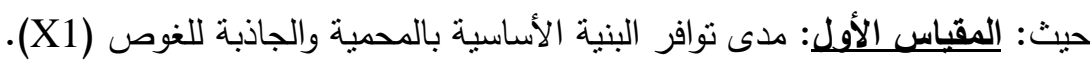
المقياس الثانى: مدى إدراك العاملين بمراكز الغوص بأهمية المحمية (X2). المقياس الثالث: مدى مساهمة الإجراءات والجهود المبذولة (X3). المقياس الرابع: مدى الحفاظ على الأنظمة البيئية البحرية (Y).

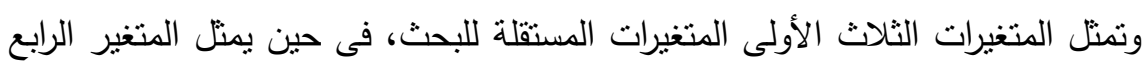

$$
\text { المتغير التابع. }
$$

تحديد الأساليب الأحصائية: قام الباحثون باستخدام الحاسب الآلى على حزم البرامج

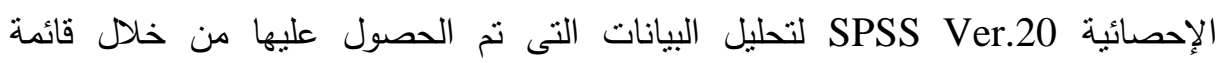
الاستقصاء، وذلك باستخدام الأساليب التالية: 
• معامل ألفا كرونباك لقياس الثبات والتحقق من درجة اعتمادية المقاييس المستخدمة. • اختبار "ت" ومستوى معنويته لقياس الصدق التمييزى. • • التكرارات والنسب المئوية لتوصيف بيانات الدراسة. • مقاييس التشتت لقياس اتجاهات عينة الدراسة. • معامل ارتباط "كندال" لقياس العلاقات الارتباطية بين المتغيرات. • تحليل التباين "ANOVA Test" لبيان قوة العلاقات الارتباطية بين المتغيرات. • معامل التحديد لبيان القيمة التفسيرية للمتغيرات المستقلة للمتغير التابع. البيانات الخاصة بالطاقة الإستيعابية للمحية: نعرض فيما يلى التكرارات والنسب المئوية البيانات الخاصة بالطاقة الإستيعابية للمحمية وتحليلها:

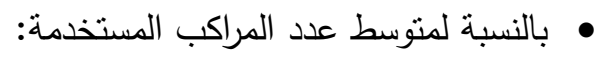

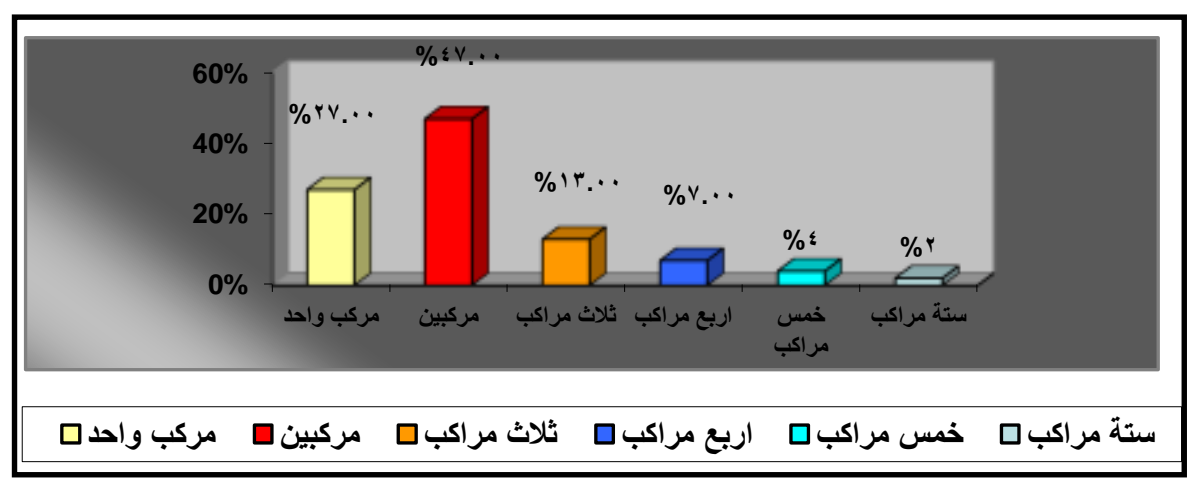
شكل(1 ) : متوسط عدد المراكب المستخدمة

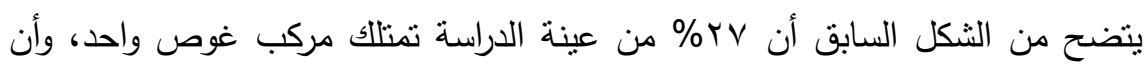

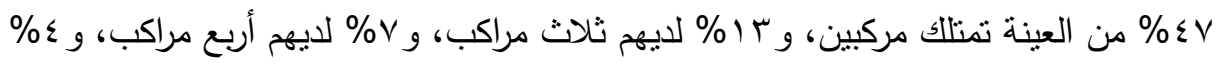

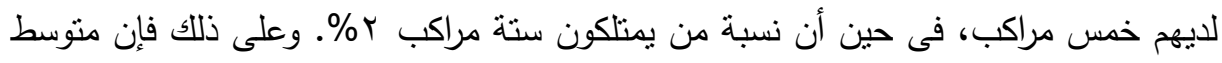

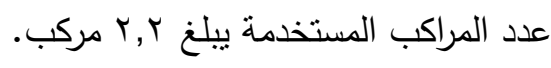


• بالنسبة لمتوسط عدد أفراد مجموعة الغطس:

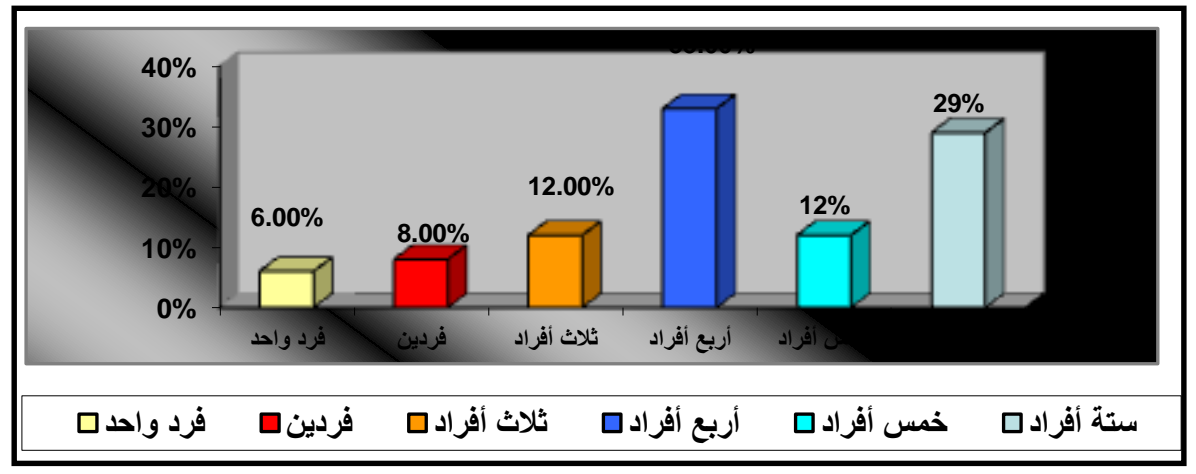

شكل(Y): منوسط عدد أفراد مجموعة الغطس

يتضح من الثكل السابق أن ج\% من عينة الدراسة تبلغ مجموعة الغطس لديهم فرد

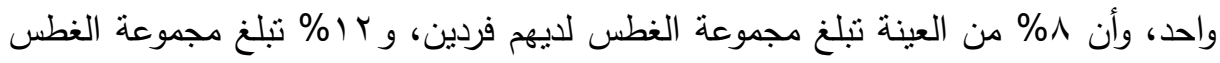

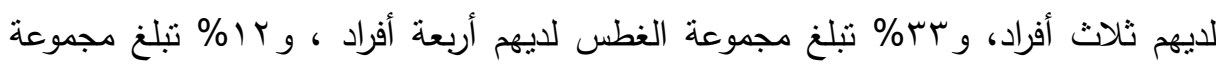
الغطس لايهه خمس أفراد، فى حين أن نسبة من تبلغ مجموعة الغطس لديهم ستة أفراد

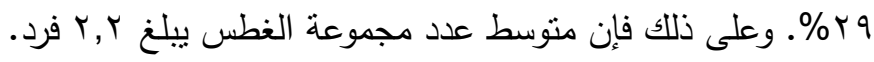
• بالنسبة لمتوسط عدد الأفراد فى كل مرة غطس:

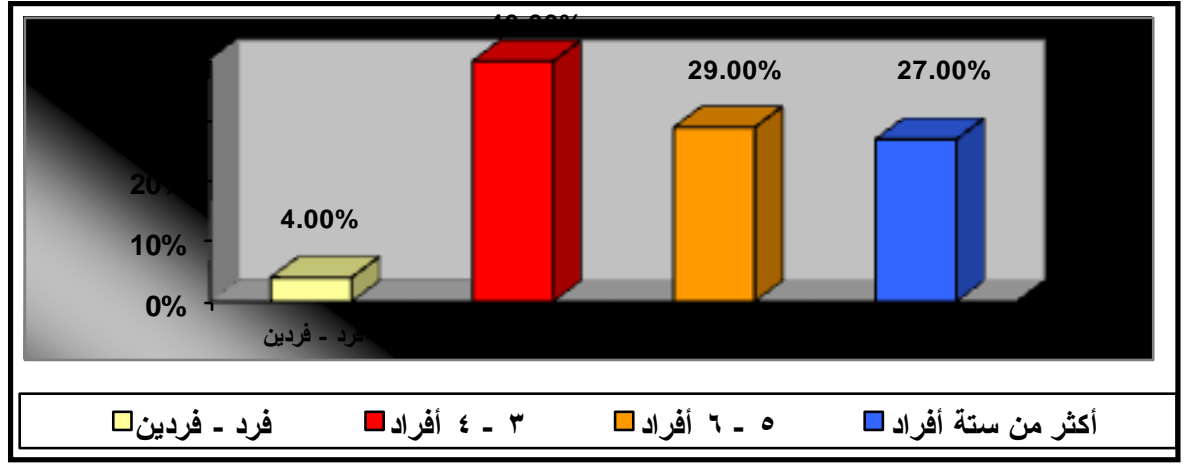

شكل(ץ): متوسط عدد الأفراد فى كل مرة غطس

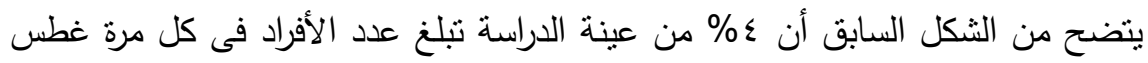

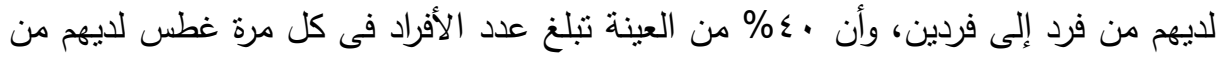

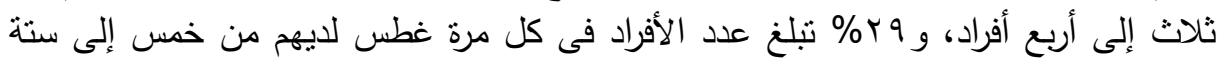
548

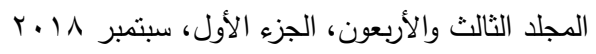


أفراد، فى حين أن نسبة من تبلغ عدد الأفراد فى كل مرة غطس لليهم أكثر من ستة أفراد

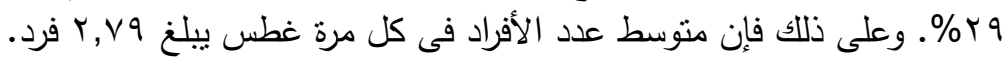

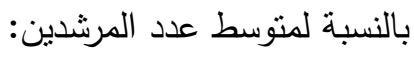

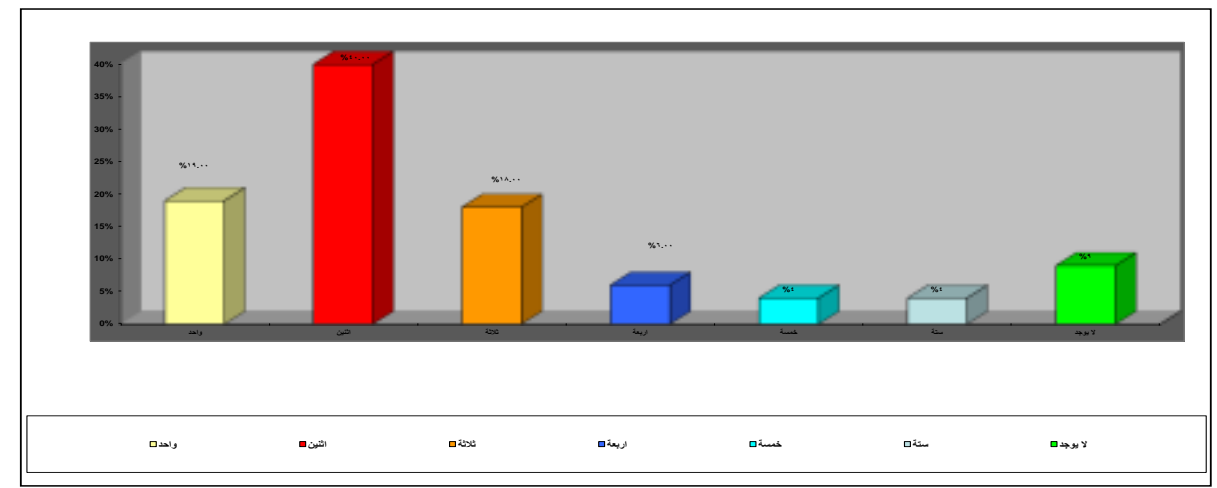

شكل (؛ ): متوسط عدد المرشدين

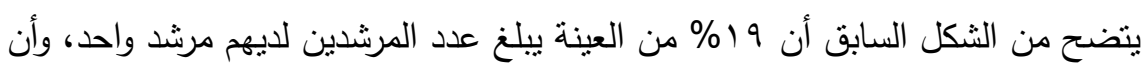

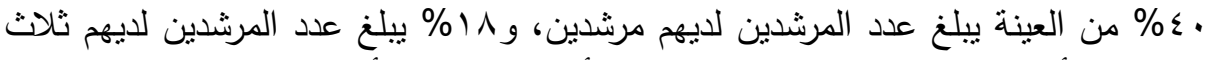

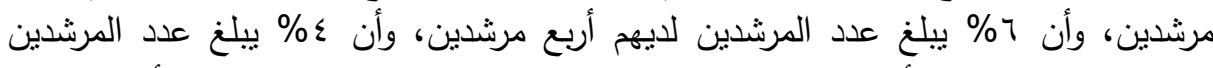

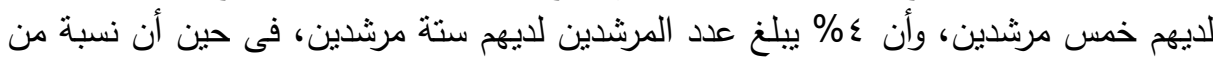

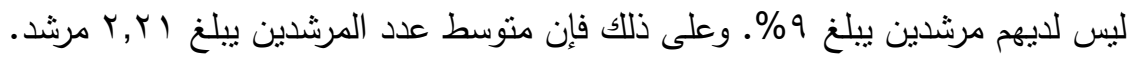
• بالنسبة لمتوسط عدد المدربين:

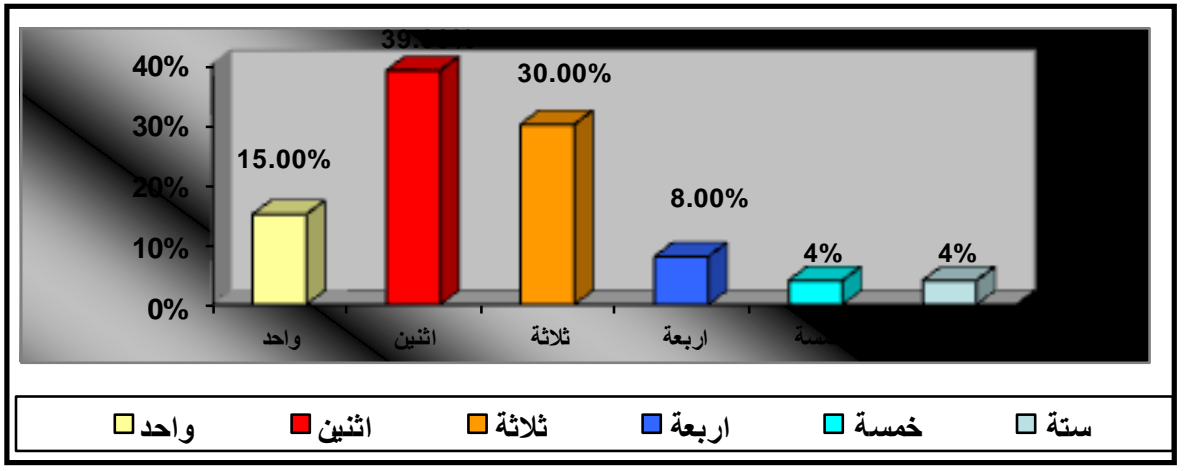

شكل(ه): منوسط عدد المدربين 
يتضح من الثكل السابق أن 9 1\% من العينة يبلغ عدد المدربين لديهم مدرب واحد، وأن

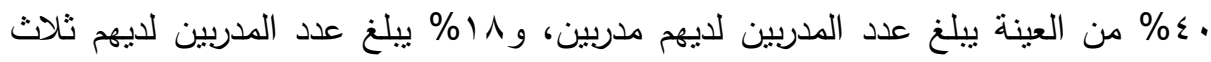

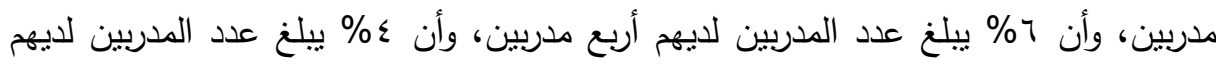

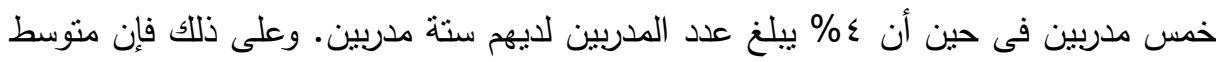

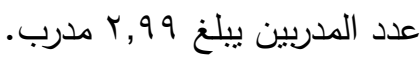
• • بالنسبة لمتوسط عدد المساعدين:

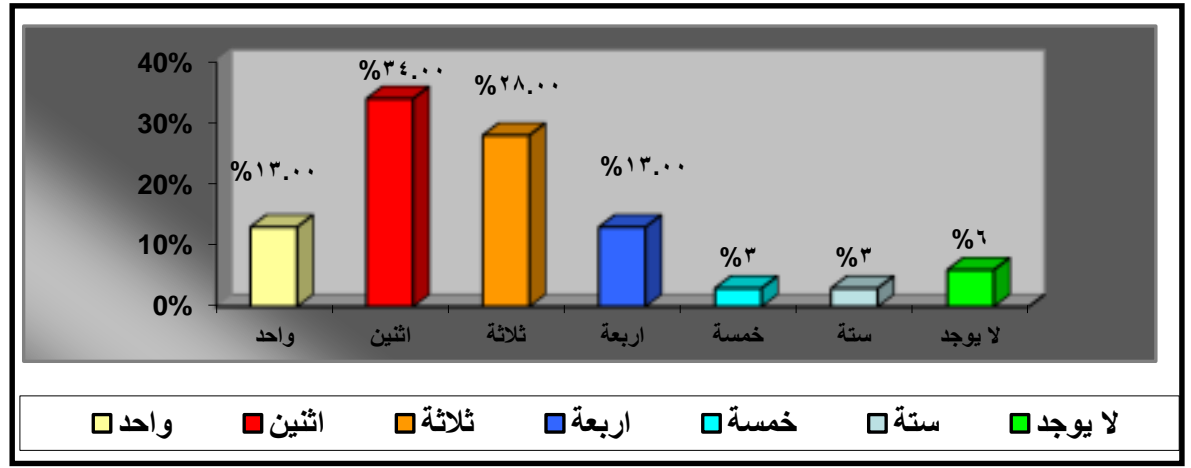

شكل( ا): منوسط عدد المساعدين

يتضح من الشكل السابق أن با \% من العينة يبلغ عدد المساعدين لديهم مساعد واحد،

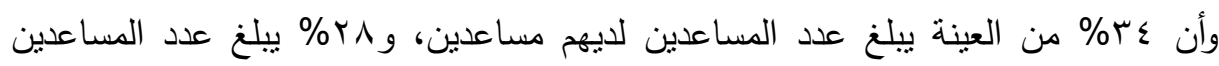

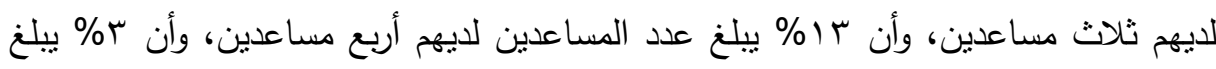
عدد المساعدين لايهم خمس مساعدين، وأن ب٪ بيلغ عدد المساعدين لديهم ستة مساعدين،

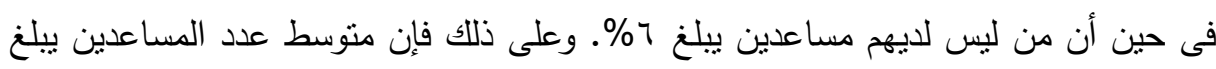
r r,O مساعد. 
• بالنسبة لعدد رحلات الغوص أسبوعياً:

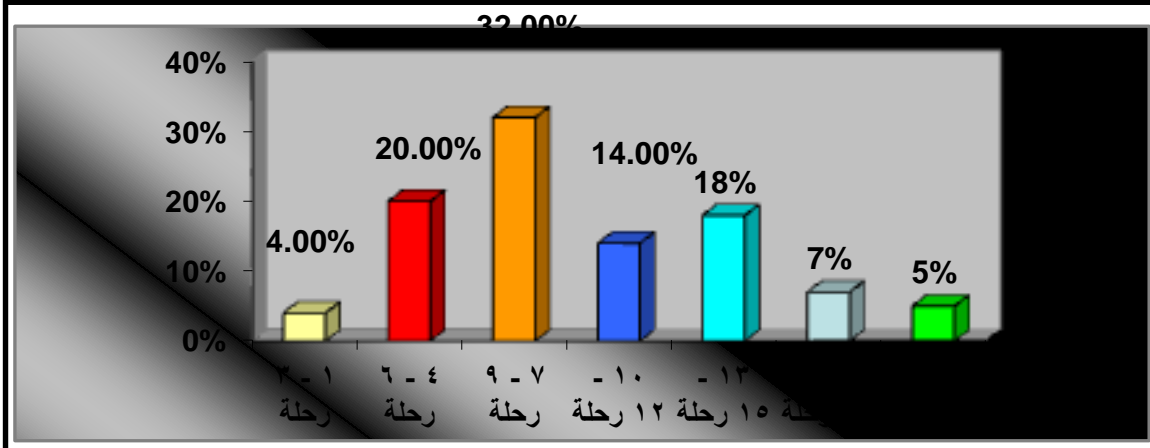

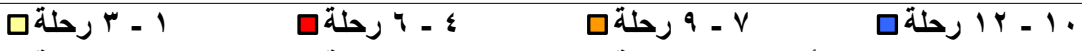

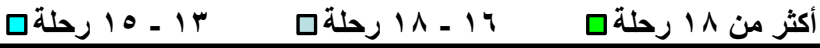

شكل(V): منوسط عدد رحلات الغوص أسبوعياً

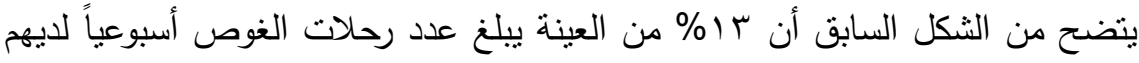

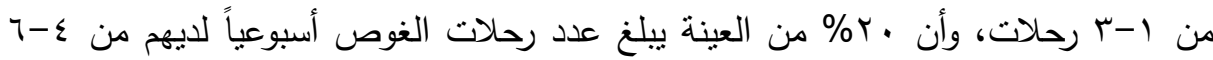

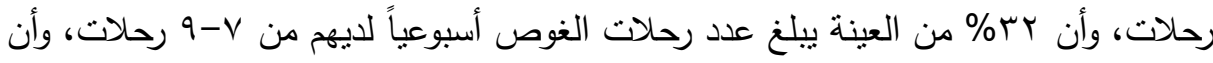

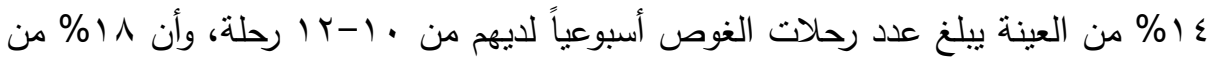

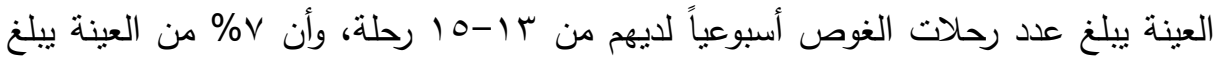

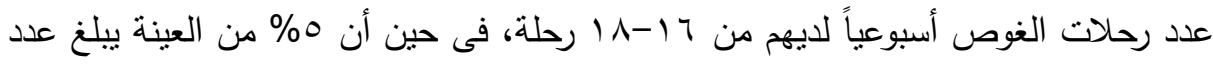
رحلات الغوص أسبوعياً لديهم أكثر من 1 ارحلة. 
• بالنسبة لعدد رحلات الغوص سنوياً:

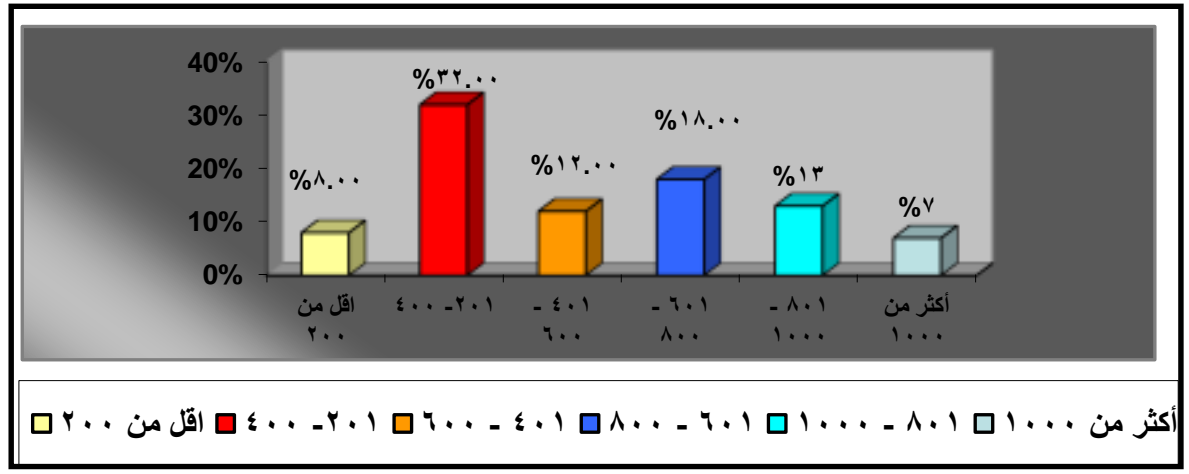

شكل(^): متوسط عدد رحلات الغوص سنوياً

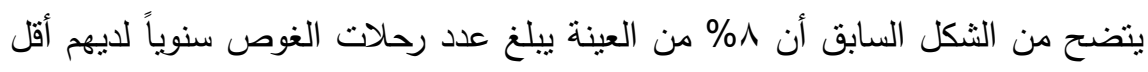

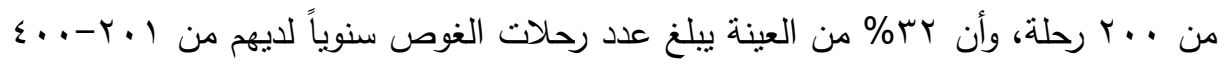

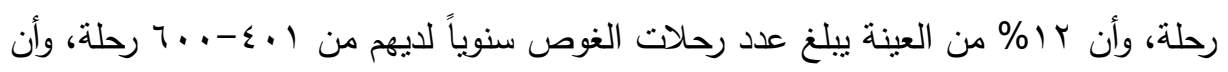

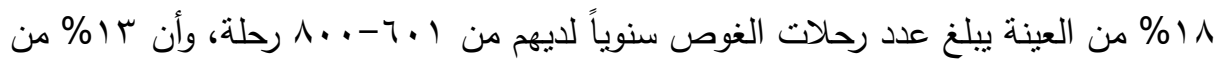

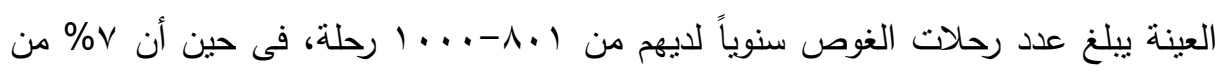

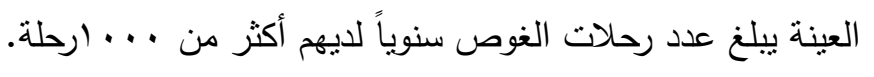

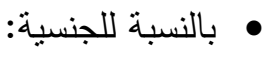

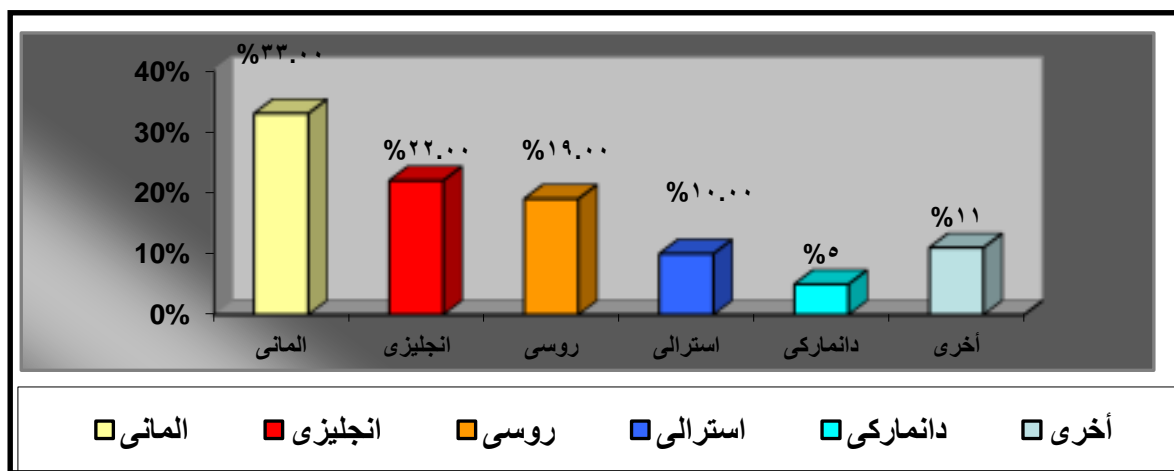

شكل(9) : يوضح انواع جنسية الزائر 


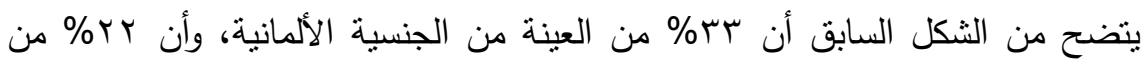

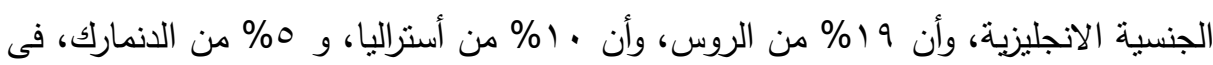

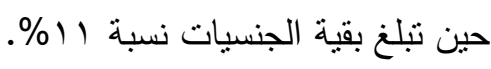
قياس ثبات استمارة الاستقصاء: يقصد بالثبات أنه لو أعيد توزيع الاستمارات على نفس عينة

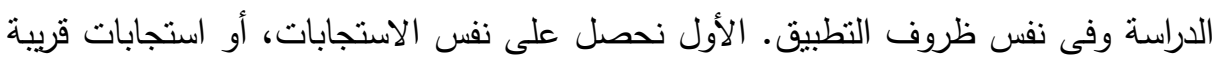
من النطبيق الأول، ويذهب علماء القياس أنه لو طبقت على عينة أخرى مسحوبة من نفس الاول

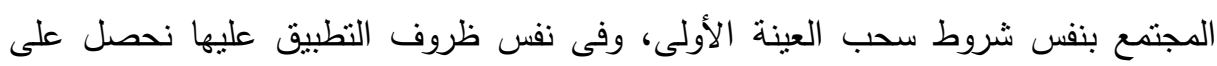

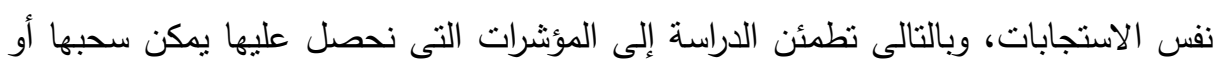

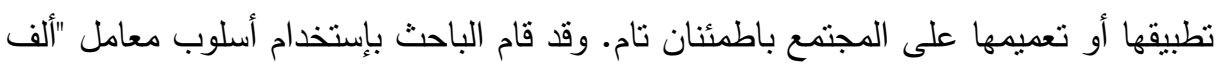

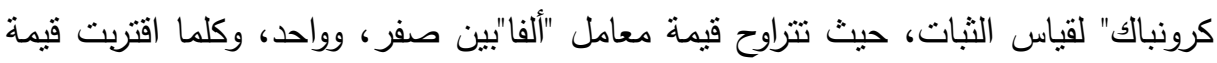

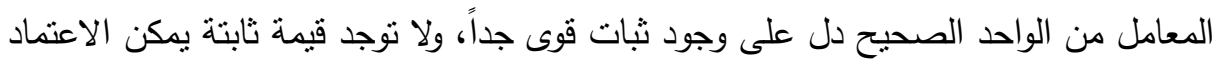

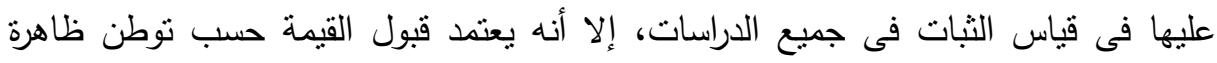
القياس فى مجتمع الدراسة وعدد العبارت التى تقيس الظاهرة البحثية ويعتمد عليها الباحث فى لئ لئه قبول درجة الثبات.

جدول( ) : معاملات الثبات لمتغيرات الدراسة باستخدام معامل ألف كرونباك

\begin{tabular}{|c|c|}
\hline معامل a a a & المتغير \\
\hline$\% ৭ \leqslant, \varepsilon$ & مدى توافر البنية الأساسية بالدحمية والجاذبة للغوص (X1). \\
\hline$\% \wedge 1, \wedge$ & مدى إدراك العاملين بمراكز الغوص بأهمية المحمية (X2). \\
\hline$\% т \vee, 1$ & مدى مساهمة الإجراءات والجهود المبذولة فى الحفاظ على المحمية (X3). \\
\hline$\% \curlyvee \wedge, r$ & مدى الحفاظ على الأنظمة البيئية البحرية (Y). \\
\hline
\end{tabular}




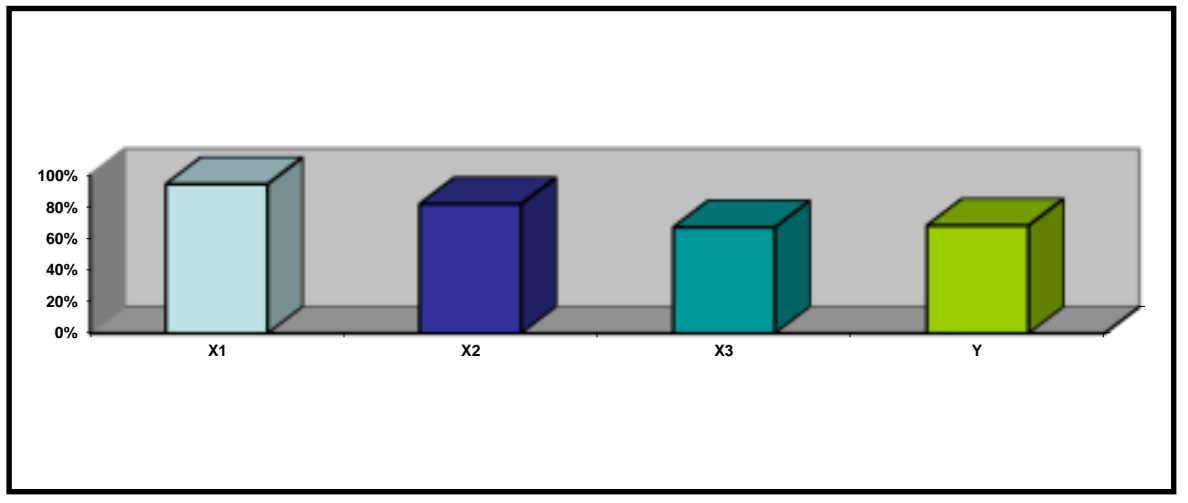

شكل( • 1 ): معاملات الثبات لعينة الدراسة

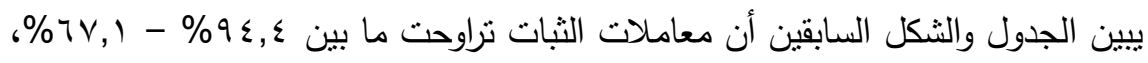
ويعكس ذلك ثبات كبير لأداة القياس ويطئن إلى ثبات آراء واتجاهات عينة البحث تجاه استمارة الاستقصاء وبدرجة عالية جداً. الصدق التمييزى لاستمارة الاستقصاء: تخضع أية ظاهرة كونية للتوزيع الطبيعى وتميز بين

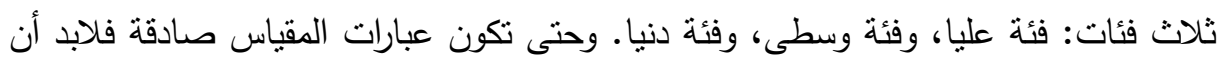
تختلف آراء واستجابات الفئة العليا لعينة الدراسة عن الفئة الدنيا، وإذا لم تختلف اتجاهات عيدات عينة الدراسة تجاه الاستجابة لعبارة ما، تصبح تلك العبارة غير صادقة حيث لم تميز بين الفئات المختلفة للعينة وبلزم حذفها. 
مجلة العلوم البيئية

معهد الدراسات والبحوث البيئة - جامعة عين شمس

جدول(Y): الصدق التمبيزى لعبارات استمارة الاستقصاء

\begin{tabular}{|c|c|c|c|c|c|c|}
\hline رقم العبارة & قيمة ت & درجات الحرية & المعنوية & متوسط الاختلافات & الفئة الانيا & الفئة العليا \\
\hline الاقبال & 33.845 & 99 & .000 & 2.56000 & 2.4099 & 2.7101 \\
\hline الكفاية & 21.910 & 99 & .000 & 1.31000 & 1.1914 & 1.4286 \\
\hline التقييم & 21.910 & 99 & .000 & 1.31000 & 1.1914 & 1.4286 \\
\hline الاهداف & 60.102 & 99 & .000 & 1.89000 & 1.8276 & 1.9524 \\
\hline الاماكن & 60.102 & 99 & .000 & 1.89000 & 1.8276 & 1.9524 \\
\hline الدراية & 43.400 & 99 & .000 & 2.99000 & 2.8533 & 3.1267 \\
\hline اجراء1 & 36.483 & 99 & .000 & 1.10000 & 1.0402 & 1.1598 \\
\hline اجراء2 & 35.549 & 99 & .000 & 2.44000 & 2.3038 & 2.5762 \\
\hline اجراء3 & 29.251 & 99 & .000 & 2.20000 & 2.0508 & 2.3492 \\
\hline اجراء4 & 47.549 & 99 & .000 & 2.65000 & 2.5394 & 2.7606 \\
\hline اجراء5 & 107.093 & 99 & .000 & 2.92000 & 2.8659 & 2.9741 \\
\hline اجراء6 & 84.912 & 99 & .000 & 2.87000 & 2.8029 & 2.9371 \\
\hline اجراء7 & 63.567 & 99 & .000 & 2.86000 & 2.7707 & 2.9493 \\
\hline التأثير & 46.766 & 99 & .000 & 2.63000 & 2.5184 & 2.7416 \\
\hline المساهمة & 33.995 & 99 & .000 & 1.64000 & 1.5443 & 1.7357 \\
\hline الضرر & 66.406 & 99 & .000 & 1.91000 & 1.8529 & 1.9671 \\
\hline ايكولوجي & 51.551 & 99 & .000 & 1.85000 & 1.7788 & 1.9212 \\
\hline
\end{tabular}

بالنظر فى الجدول السابق ينضح اختلاف اتجاهات عينة الدراسة بجميع فئاتها، أى أن عينة البحث أدركت وميزت محتوبات استمارة الاستقصاء على اختلاف خبراتهم وثقافتهم وميولهم. مما سبق وبناء على نتائج قياس التبات، والصدق التمبيزى أصبحت استمارة الاستقصاء ثابتة وصادقة فى قياسها لمتغيرات الدراسة.

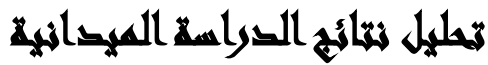

• نتائج الدراسة الميدانية لمتغير مدى توافر البنية الأساسية بالمحمية والجاذبة للغوص $:(\mathrm{X} 1)$

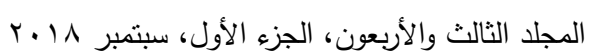




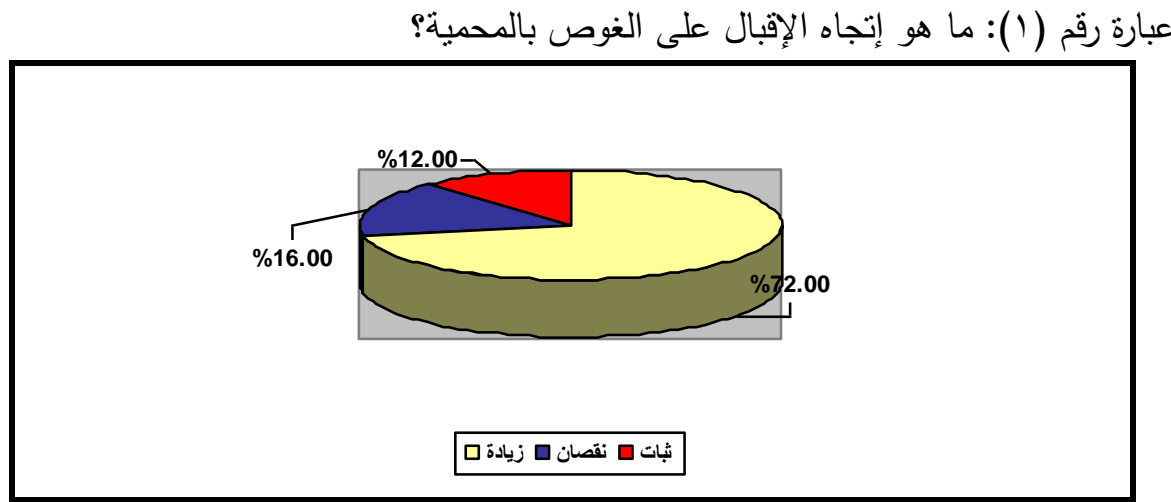

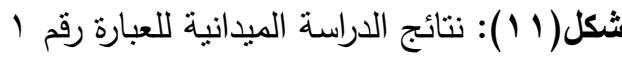

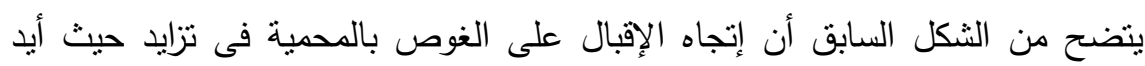

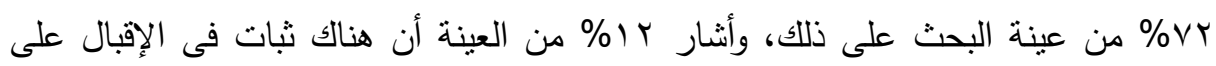

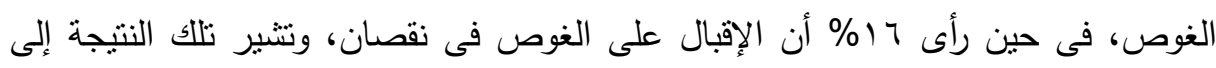

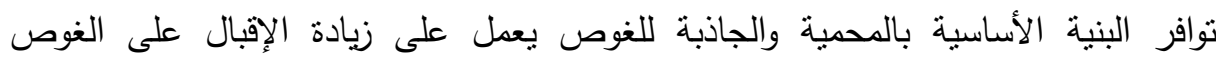

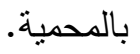
عبارة رقم (Y): هل تعتقد بكفاية فريق عمل الغوص بالمحمية من مدربين وخلافه؟

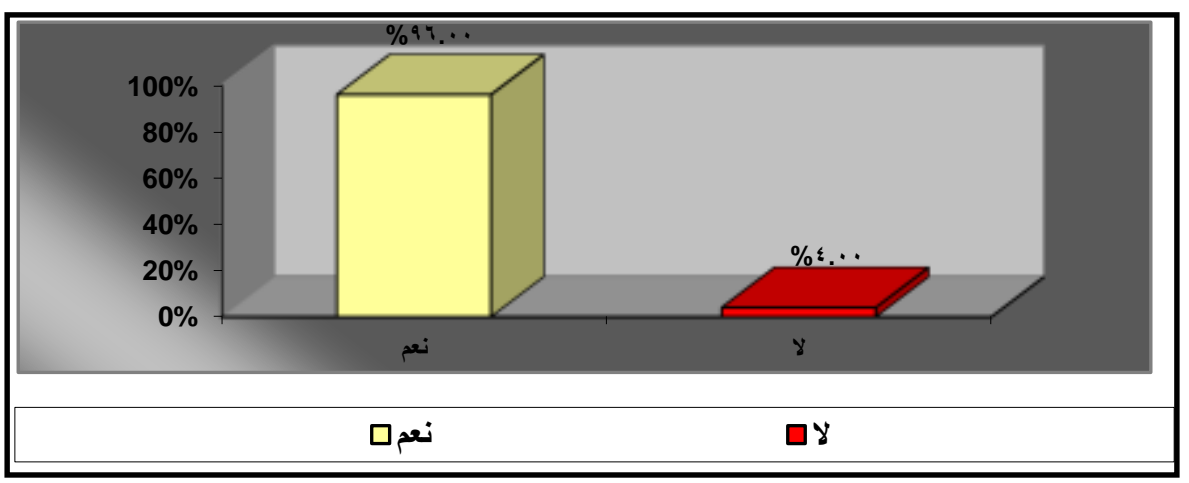

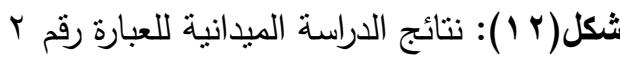

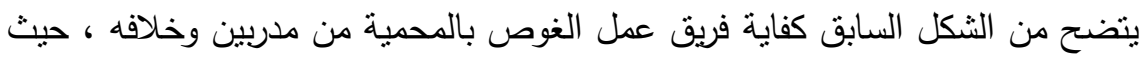

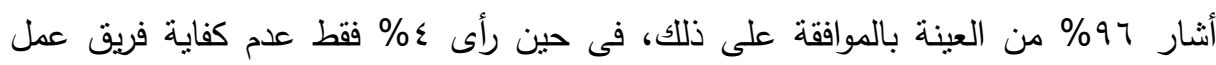


الغوص بالمحمية، وتثير تلكك النتيجة إلى توافر البنية الأساسية بالمحمية والجاذبة للغوص من مدربين وخلافه. عبارة رقم (r): ما تقييمك لحالة المحمية كمكان جاذب للغوص مقارنة بالمحميات الأخرى؟

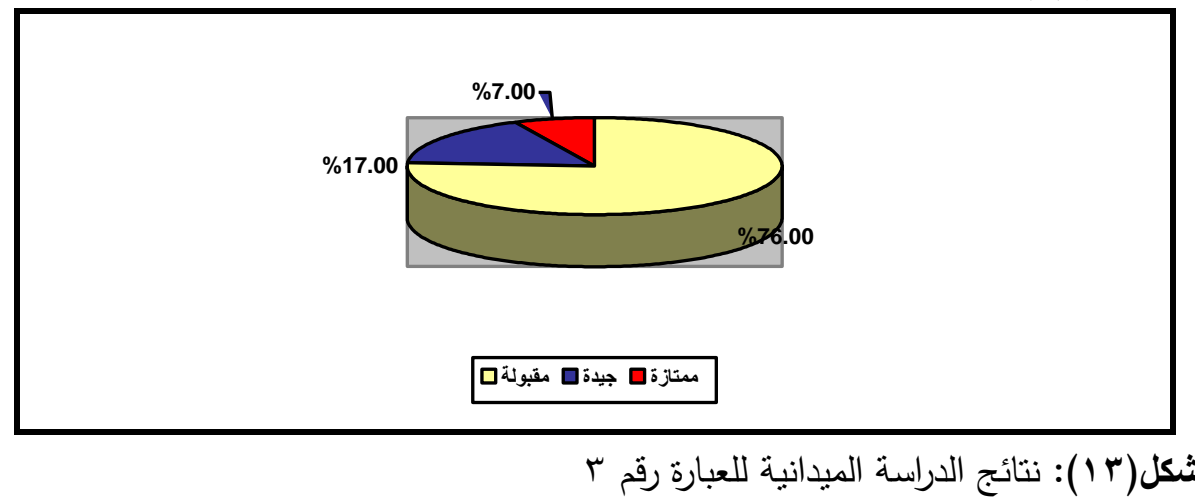

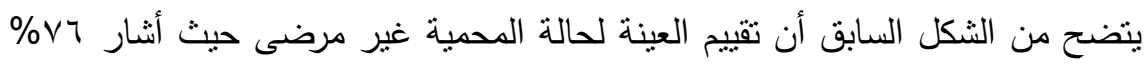

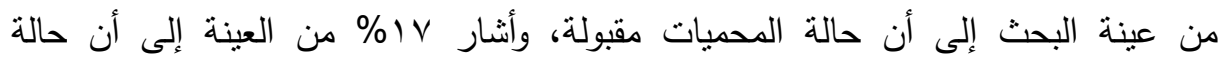

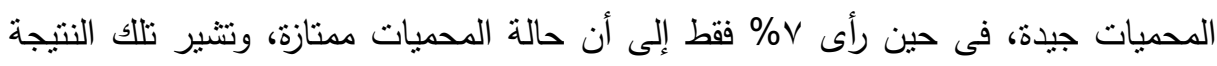
إلى ضعف حالة المحميات والذر قد يؤثر على جاذبية الغوص بالمحمية. • نتائج الدراسة الميدانية لمتغير مدى إدراك العاملين بمراكز الغوص بأهمية المحمية (X2): عبارة رقم (ع): هل أنت على دراية بأهداف وكيفية الحفاظ على المحمية؟ إنى

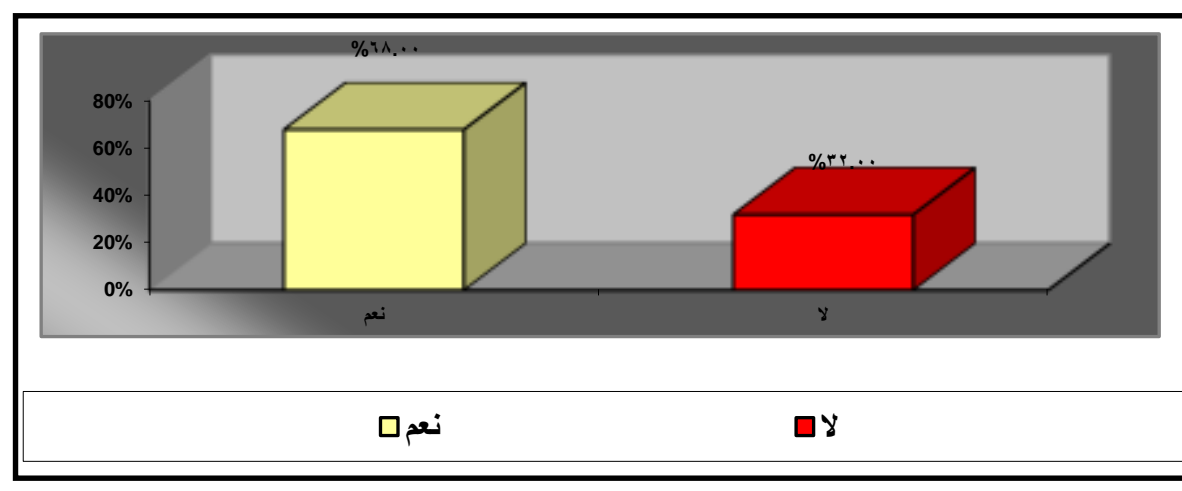

شكل( ؛ 1 ): نتائج الدراسة الميدانية للعبارة رقم ع

المجلد الثالث والأربعون، الجزء الأول، سبتمبر 11 ـ ب 
يتضح من الثكل السابق أن معظم العاملين بمجال الغوص على دراية بأهداف وكيفية

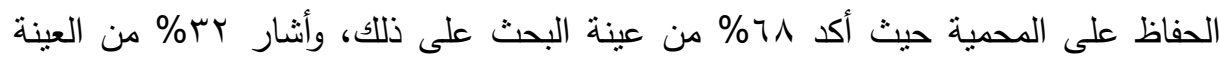
بعكس ذلك، وتتير تلك النتيجة إلى إدراك العاملين بمراكز الغوص بأهمية المحمية بشكل مرضى. عبارة رقم (0): هل تخبر من يقومون بالغطس بحالة المحمية والأماكن التى يمكنهم ممارسة الأنشطة بها؟

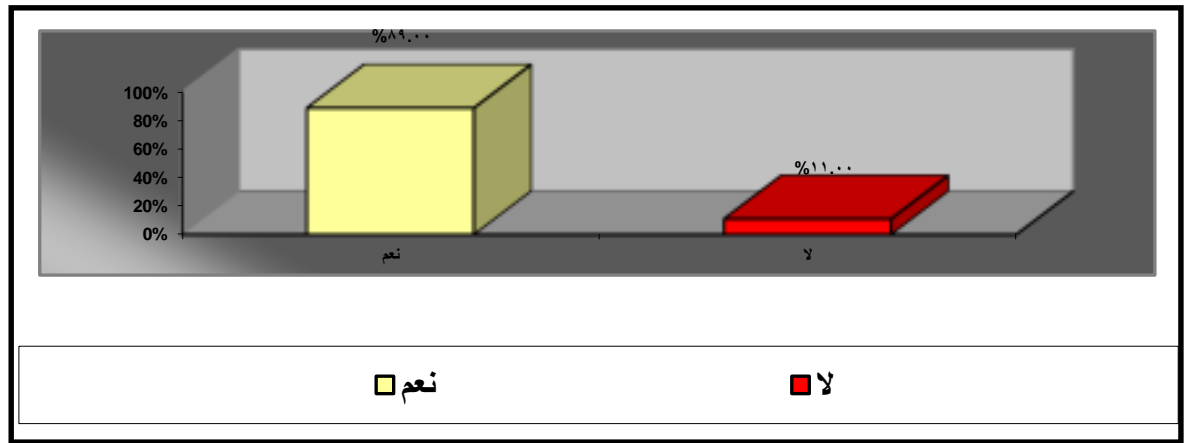

شكل(0 1 ): نتائج الدراسة الميدانية للعبارة رقم

يتضح من الثكل السابق أن معظم العاملين يخبرون من يقومون بالغطس بحألة بحالة المحمية

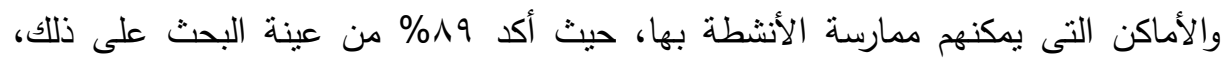

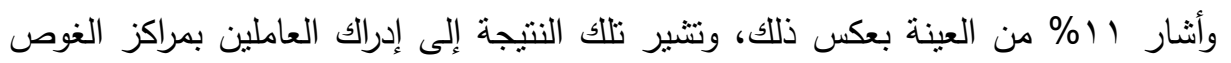
بأهمية الحفاظ على المحمية بشكل مرضى.

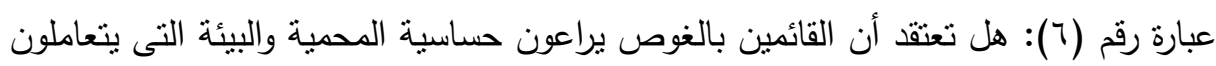
معها؟ 


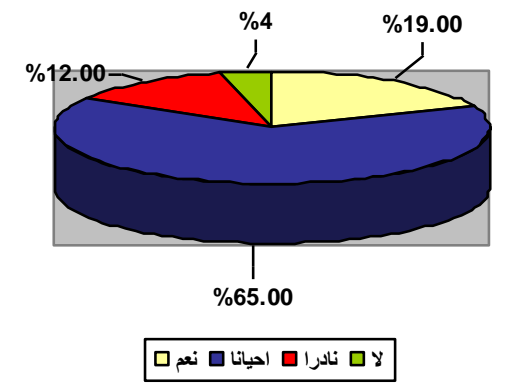

شكل(1 1 ): نتائج الدراسة الميدانية للعبارة رقم 1 (أن

يتضح من الثكل السابق أن 9 1\% من القائمين بالغوص يراعون حساسية المحمية

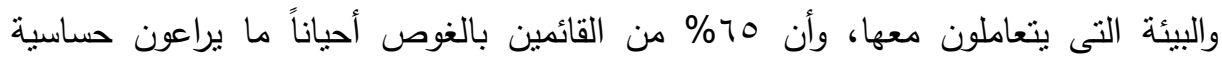

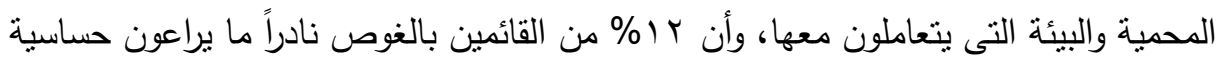

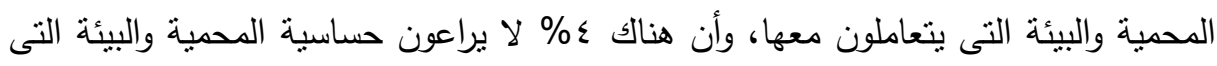

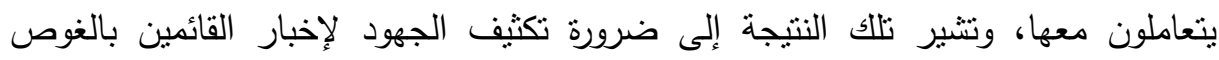
بأهمية مراعاة حساسية المحمية والبيئة التى ينعاملون معها.

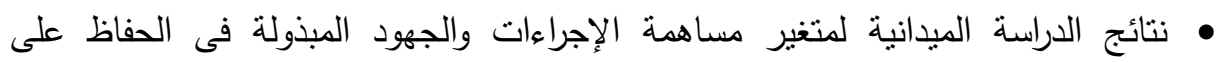
المحمية (X3):

عبارة رقم (V): أياً من الإجراءات نراها يمكن أن تساهم فى الحفاظ على المحمية؟

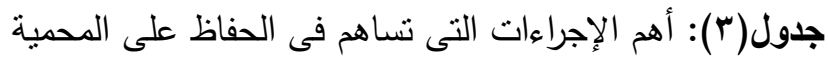

\begin{tabular}{|c|c|c|}
\hline الترتيب من حيث الأهمية & المتوسط & الإجراء \\
\hline $\mathrm{v}$ & 1,1 & () تحديد عدد زائرى المحمية \\
\hline 0 & $Y, \Sigma \varepsilon$ & r) تحديد عدد الغواصين فى المجموعة الواحدة \\
\hline 7 & $r, Y$ & r) تحديد عدد مجموعات الغطس فى نفس التوقيت \\
\hline$\varepsilon$ & $r, 70$ & عالاخول اعتمادا على خبرتهم بالغطين وفقا لصعوبة المحمية والسماح \\
\hline 1 & r,9 & 0) التأكبد على الغواصين بمراعاة عدم كسر أو أخذ الثعاب \\
\hline r & $r, \wedge V$ & 7) مراعاة عدم الرسو على أماكن الشعاب \\
\hline r & $Y, \wedge \uparrow$ & V Vعريف الغواصين بالمحظورات الموجودة بالمحمية \\
\hline
\end{tabular}


يتضح من الجدول السابق أن أهم الإجراءات التى يمكن أن تساهم فى الحفاظ على

$$
\text { المحمية هى على الترتيب: }
$$

1. التأكيد على الغواصين بمراعاة عدم كسر أو أخذ الثعاب.

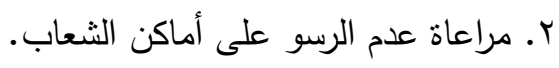

r. تعريف الغواصين بالمحظورات الموجودة بالمحمية.

ع. تصنيف الغطاسين وفقا لصعوبة المحمية والسماح بالدخول اعتمادا على خبرتهم بالغطس.

ه. تحديد عدد الغواصين فى المجموعة الواحدة.

7 . تحديد عدد مجموعات الغطس فى نفس التوقيت.

V. تحديد عدد زائرى المحمية.

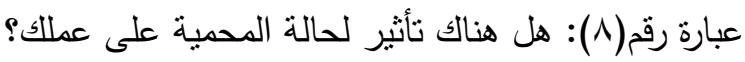

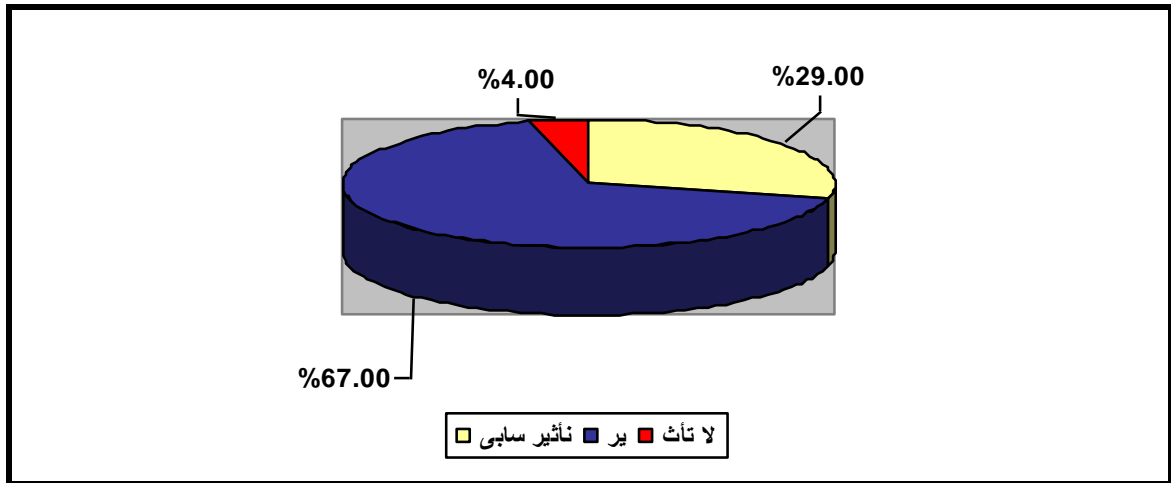

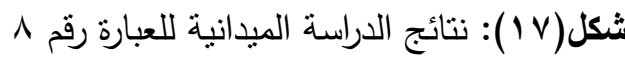

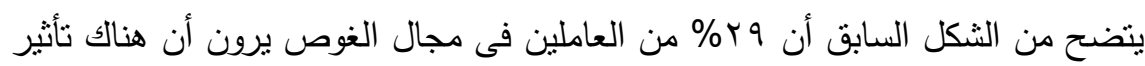

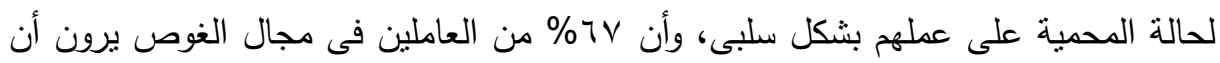

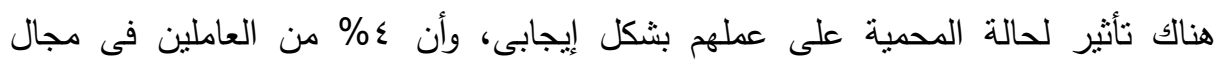
الغوص يرون أنه ليس هناك تأثير لحالة المحمية على عملهم. عبارة رقم (9): هل توافق على المساهمة ببعض الرسوم الرمزية لإنفاقها فى الحفاظ على حالة

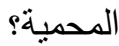




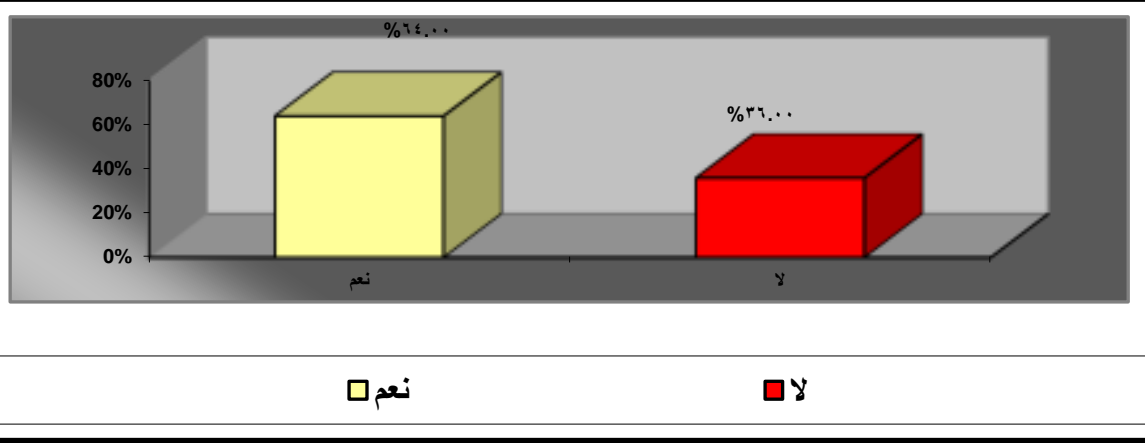

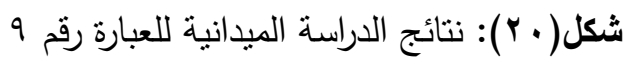

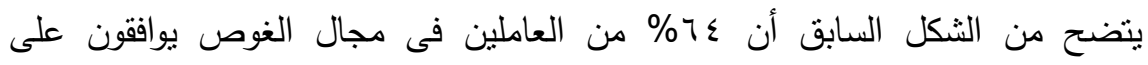

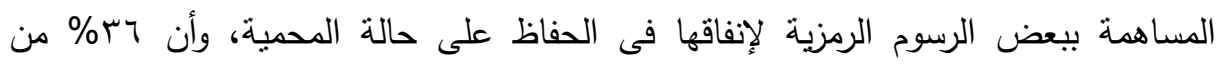
العاملين لا يوافقون على ذلك. • ن نتائج الدراسة الميدانية لمتغير مدى الحفاظ على الأنظمة البيائية البحرية (Y):

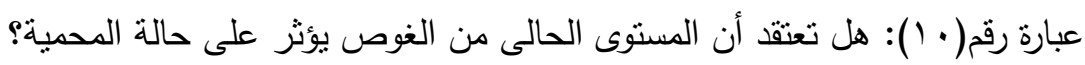

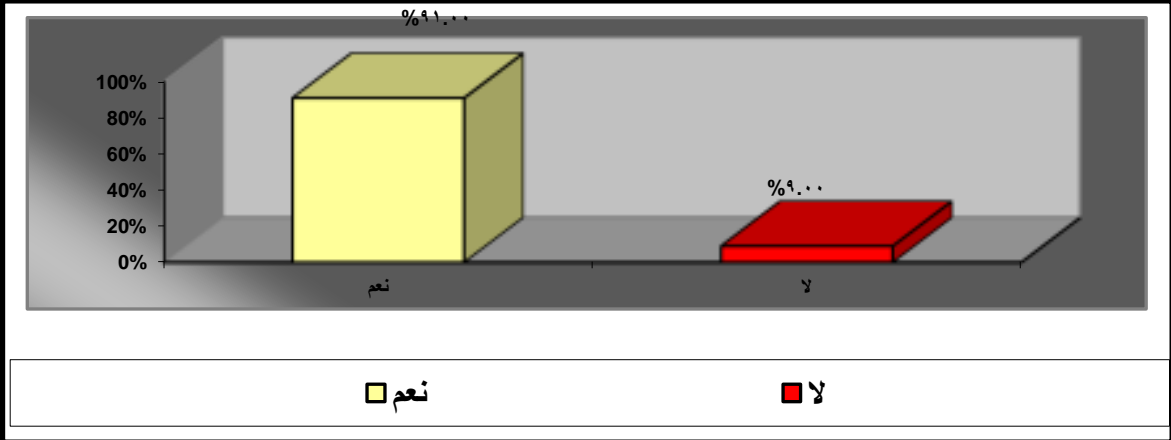

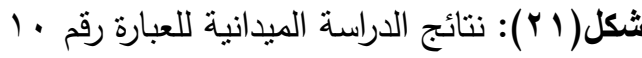

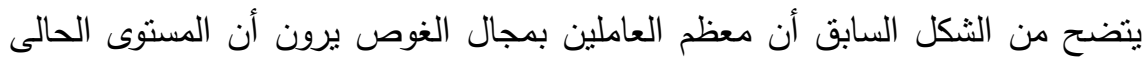

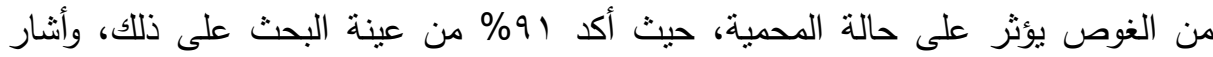
\% فقط من العينة بعكس ذلك، وتتير تلكك النتيجة إلى إدراك العاملين بمراكز الغوص بأهمية الحفاظ على الأنظمة البيئية البحرية بشكل كبير جداً.

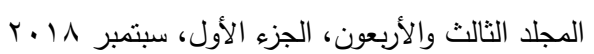


عبارة رقم (1): هل القائمين بالغطس على علم كاف بتأثثر عمليات الغوص على النظام

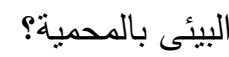

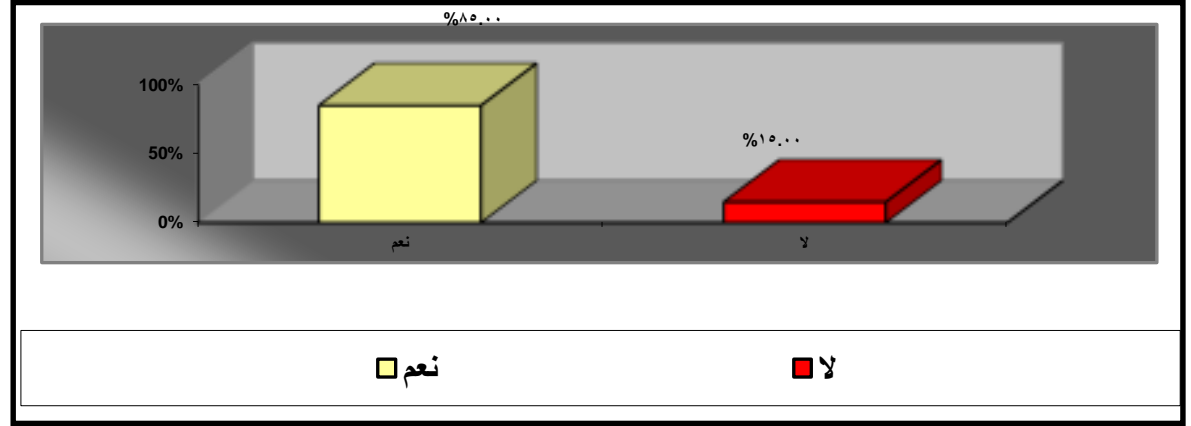

شكل(Y r r): نتائج الدراسة الميدانية للعبارة رقم 11 يتضح من الثكل السابق أن معظم القائمين بالغطس على علم كاف بتأثير عمليات الغوص على النظام البيئى بالمحية، حيث أكد مر0\% من عينة البحث على ذلك، وأثنار 1\% فقط من العينة بعكس ذللك، وتثير تلك النتيجة إلى إدراك القائمين بالغطس بتأثير عمليات الغوص على النظام البيئى بالمحية مما يساهم بشكل كبير فى الحفاظ على البيئة.

\section{الخمهار هغوضر التواسـا}

اختبار الفرض الأول: يوجد إرتباط ذو دلالة معنوية لتوافر البنية الأساسية بالمحمية والجاذبة للغوص ويين حماية الأنظمة البيئية البحرية". معاملات الارتباط للفرض الأول: يبين جدول معاملات الارتباط بين المتغير المستقل والمتمثل لئل فى مدى توافر البنية الأساسية بالدمية والجاذبة للغوص وبين حماية الأنظمة البيئية البحرية كمتغير تابع باستخدام معامل ارتباط "كندال".

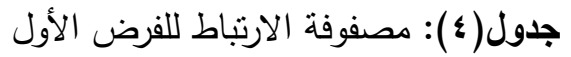

\begin{tabular}{|c|c|c|c|}
\hline المتغير التابع & المعنوية & معامل ارتباط كندال & المتغير المستقل \\
\hline \multirow{3}{*}{ حماية الأنظمة البيئية البحرية } & $\cdot, \cdots$ & ("**)., हYr & \multirow{3}{*}{ بالمحمبة والجاذبة للغوص البناسية } \\
\hline & $\cdot,, \cdots$ & $\left({ }^{\circ *}\right), r \vee Y Y$ & \\
\hline & $\cdot, \ldots q$ & $\left({ }^{(*)}\right) \cdot, .90$ & \\
\hline
\end{tabular}

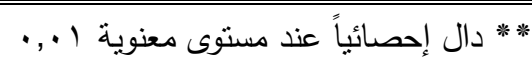


بالنظر فى الجدول السابق يتضح وجود ارتباط جوهرى عند مستوى معنوية ا +,. بين توافر البنية الأساسية بالمحمية والجاذبة للغوص وبين حماية الأنظمة البيئية البحرية. تحليل التباين "ANOVA Test" تلفرض الأول:

\begin{tabular}{|c|c|c|c|c|}
\hline \multicolumn{2}{|c|}{ اختبار " ف " } & متوسط المريعات & مجموع المريعات & البيان \\
\hline المعنوية & القيمة & $I r \cdot r \cdot r$ & ס."ז, . ז & الانحدار \\
\hline$(* *), \ldots$ & qะ., TrV & $\cdot, 1 Y \Lambda$ & $1 Y, 490$ & الخطأ \\
\hline
\end{tabular}

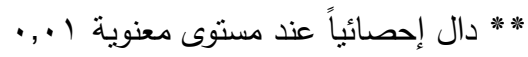

بالنظر فى جدول تحليل التباين السابق يتضح وجود علاقة انحدارية طردية بين نوافر

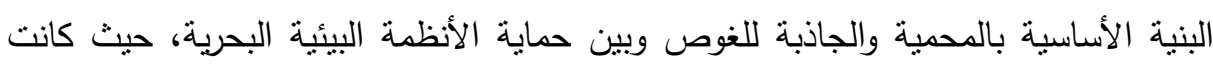

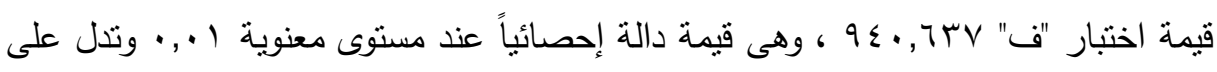
صحة العلاقة الانحدارية وجوهرية العلاقة بين المتغيرين؛ حيث كلما نوافرت مقومات البنية الأساسية بالمحية والجاذبة للغوص، كلما أدى ذلك إلى دعم وحماية الأنظمة البيئية البحرية.

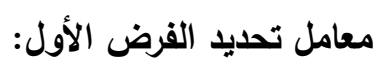
جدول(؟): معامل تحديد الفرض الأول

\begin{tabular}{|c|c|c|c|}
\hline الذطأ المعيارى & $\mathbf{R}$ & $\mathbf{R}^{r}$ & البيان \\
\hline$\cdot, r \circ V \leqslant V$ & מקו, & $\cdot, 97 V$ & معامل التحديد \\
\hline
\end{tabular}

يبين الجدول السابق أن معامل التحديد

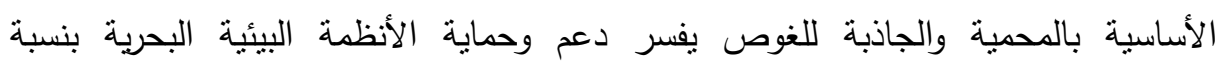
\%9 \%, > إلى الأخطاء العشوائية الناتجة عن أسلوب سحب العبه العينة ودقة القياس وغيرها.

مما سبق يتضح صحة الفرض الأول: "يوجد إرتباط ذو دلالة معنوية لتوافر البنية الأساسية بالمحمية والجاذبة للغوص وبين حماية الأنظمة البيئية البحرية". 
اختبار الفرض الثانى: "يوجد إرتباط ذو دلالة معنوية بين إدراك العاملين بمراكز الغوص بأهمية المحمية ويين حماية الأنظمة البيئية البحرية". معاملات الارتباط للفرض الثانى: يبين جدول معاملات الارتباط بين المتغير المستقل والمتمثل

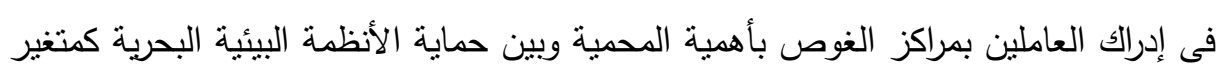
تابع باستخدام معامل ارتباط "كندال".

\begin{tabular}{|c|c|c|c|}
\hline & & باط للفرض الثانى & جدول(V): مصفوفة الا \\
\hline المتغير التابع & المغنوية & معامل ارتباط كندال & المتغير المستقل \\
\hline \multirow{3}{*}{ حماية الأنظمة البيئية البحرية } &.,$\ldots 0$ & ("*).,.rr & \multirow{3}{*}{ إلغرص بأهمية المحلين بمراكزية } \\
\hline & $\cdot, \ldots 1$ & $(" * *) \cdot, \cdot 1$. & \\
\hline & $\cdot, \ldots r$ & $\left({ }^{(* *)} \cdot, 109\right.$ & \\
\hline
\end{tabular}

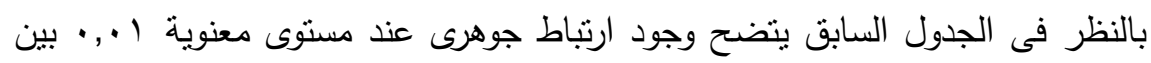

إدراك العاملين بمراكز الغوص بأهمية المحمية وبين حماية الأنظمة البيئية البحرية. تحليل التباين "ANOVA Test" للقرض الثانى:

\begin{tabular}{|c|c|c|c|c|}
\hline & & \multicolumn{3}{|c|}{ جدول(^): تحليل التباين للفرض الثانى } \\
\hline \multicolumn{2}{|c|}{ اختبار " ف " } & متوسط المربعات & مجموع المربعات & البيان \\
\hline لم المعنوية & القيمة & $119, \wedge \leqslant 0$ & ro9,0rs & الانحدار \\
\hline$\left({ }^{* *}\right), \ldots$ & טדז,ז. & $\cdot, 1+9$ & $1 T, \leq 77$ & الخطأ \\
\hline
\end{tabular}

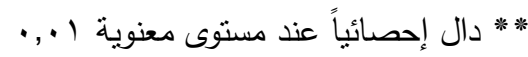

بالنظر فى جدول تحليل التباين السابق يتضح وجود علاقة انحدارية طردية بين إدراك

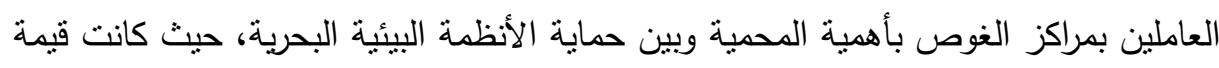

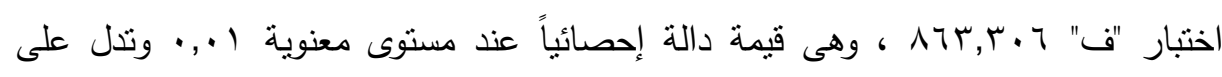
صحة العلاقة الانحدارية وجوهرية العلاقة بين المتغيرين؛ حيث كلما زاد إدراك العاملين بمراكز الغوص بأهمية المحمية، كلما أدى ذلك إلى دعم وحماية الأنظمة البيئية البحرية. 
معامل تحديد الفرض الثانى:

\begin{tabular}{|c|c|c|c|}
\hline & & \multicolumn{2}{|c|}{ جدول(9): معامل تحديد الفرض الثانى } \\
\hline الخطأ المعيارى & $\overline{\mathbf{R}}$ & $\overline{\mathbf{R}^{r}}$ & البيان \\
\hline , rVYOq & . $9 \Delta \mathrm{r}$ & ., $97 \varepsilon$ & معامل التحديد \\
\hline
\end{tabular}

يبين الجدول السابق أن معامل التحديد

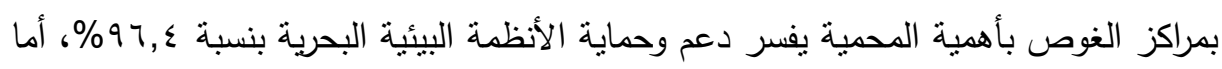
النسبة الباقية فتفسرها متغيرات أخرى لم تدخل فى العلاقة الانحدارية بالإضافة إلى الأخطاء العشوائية الناتجة عن أسلوب سحب العينة ودقة القياس وغيرها. مما سبق يتضح صحة الفرض الثانى: "يوجد إرتباط ذو دلالة معنوية بين إدراك العاملين بمراكز الغوص بأهمية المحمية وبين حماية الأنظمة البيئية البحرية". اختبار الفرض الثالث: "يوجد إرتباط ذو دلالة معنوية بين الإجراءات والجهود المبذولة فى الحفاظ على المحمية ويين حماية الأنظمة البيئية البحرية". معاملات الارتباط للفرض الثالث: يبين جدول معاملات الارتباط بين المتغير المستقل والمتمنل الانله فى الإجراءات والجهود المبذولة فى الحفاظ على المحمية وبين حماية الأنظمة البيئية البحرية كمتغير تابع باستخدام معامل ارتباط "كندال". جدول( • 1): مصفوفة الارتباط للفرض الثالث

\begin{tabular}{|c|c|c|c|}
\hline المتغير التابع & المعنوية & معامل ارتباط كندال & المتغير المستقل \\
\hline \multirow{9}{*}{ حماية الأنظمة البيئية البحرية } &,$\ldots \wedge$ & $\left({ }^{(* *)} \cdot, r \leq r\right.$ & \multirow{9}{*}{ الإجبذاءوات والجهود الحفاظ } \\
\hline &,$\ldots \leq$ & $(* *) \cdot, \cdot r \mu$ & \\
\hline & $\cdot, \ldots r$ & (**)., • ("TV & \\
\hline &.,$\ldots 7$ & $\left({ }^{* *}\right) \cdot, 0.9$ & \\
\hline & $\cdot, \cdots 9$ & $(* *) \cdot, .94$ & \\
\hline &.,$\ldots r$ & 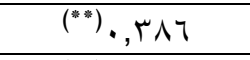 & \\
\hline &,,$\cdots$ & $(* *) \cdot, \wedge 9 \wedge$ & \\
\hline & $\cdot, \ldots r$ & $(* *) \cdot, Y 9 Y$ & \\
\hline &.,$\ldots r$ & $(* *) \cdot, 11 V$ & \\
\hline
\end{tabular}

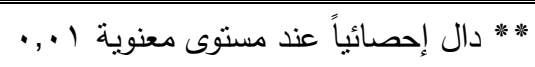

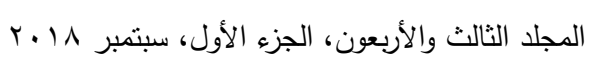


بالنظر فى الجدول السابق يتضح وجود ارتباط جوهرى عند مستوى معنوية ا.,., بين

الإجراءات والجهود المبذولة فى الحفاظ على الهحمية وبين حماية الأنظمة البيئية البحرية. تحليل التباين "ANOVA Test" للفرض الثانى: جدول(11 1 ): تحليل التباين للفرض الثالث

\begin{tabular}{|c|c|c|c|c|}
\hline \multicolumn{2}{|c|}{ اختبار " ف " } & متوسط المربعات & مجموع المربعات & البيان \\
\hline المعنوية & القيمة & $\varepsilon \cdot, O Y \Lambda$ & rฯ\&,V०O & الانحدار \\
\hline$(* *)$, & $\varepsilon \varepsilon V, r \mid r$ & $0 ., 91$ & $\Lambda, r \leqslant 0$ & الخطأ \\
\hline
\end{tabular}

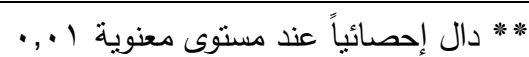

بالنظر فى جدول تحليل التباين السابق يتضح وجود علاقة انحدارية طردية بين الإجراءات والجهود المبذولة فى الحفاظ على المحية وبين حماية الأنظمة البيئية البحرية،

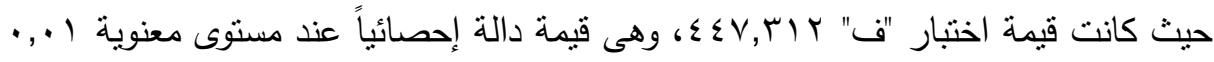
وتدل على صحة العلاقة الانحدارية وجوهرية العلاقة بين المتغيرين؛ حيث كلما زادت الإجراءات والجهود المبذولة فى الحفاظ على المحمية، كلما أدى ذلك إلى دعم وحماية الأنظمة لئل البيئية البحرية. معامل تحديد الفرض الثالث: - مائه

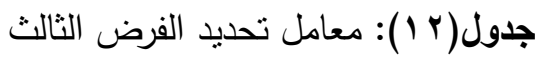

\begin{tabular}{|c|c|c|c|}
\hline الخطأ المعيارى & $\mathbf{R}$ & $\overline{\mathbf{R}^{r}}$ & البيان \\
\hline$\cdot, r \cdot 1 \cdot 1$ & $\cdot, 9 \wedge 9$ & $\cdot, 9 \vee \wedge$ & معامل التحديد \\
\hline
\end{tabular}

يبين الجدول السابق أن معامل التحديد

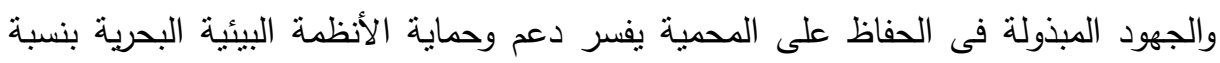

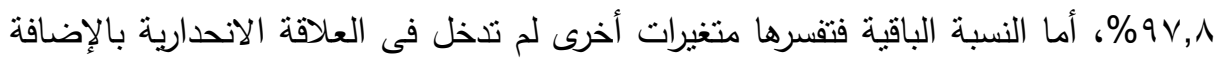
إلى الأخطاء العشوائية الناتجة عن أسلوب سحب العينة ودقة القياس وغيرها.

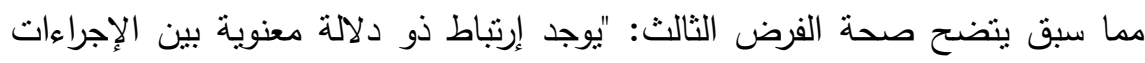
والجهود المبذولة فى الحفاظ على المحمية وبين حماية الأنظمة البيئية البحرية". 


\section{الالنمائية}

() تعدد الجهات المكلفة بتتفيذ التشريعات البيئية وعدم التتسيق بينها، حيث تثارك الهيئات المتعددة جهاز شئون البيئة فى تتفيذ أحكام القانو نلسنة ؟9 99 الكمصلحة الموانى والمنائر

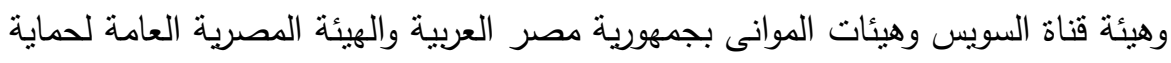
شواطىء الهيئة المصرية العامة للبترول والهيئة العامة لتتمية السياحة والإدارة العامة لشرطة المسطحات والبيئة - الأمر الذى يتطلب إيجاد أنواع من تتسيق بين الوزارات والهيئات.

r) نقص المعلومات البيئية التى تعين على التعرف على حالة البيئة البحرية وتحديد اسباب التدهور الناجم عن تجاوز الحدود القصوى للطاقة الاستبعابية.

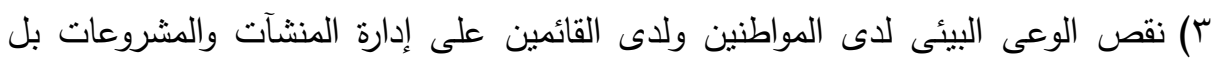

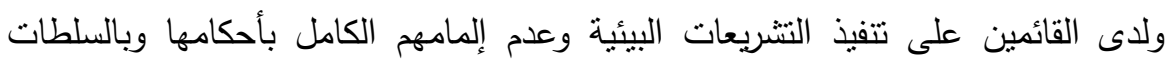
المخولة لهم بموجبها الأمر الذى ينطلب العمل على رفع الوعى البيئى وعقد دورات للتنقيف البيئى والتعريف بالتشريعات البيئية وتدريب القائمين على تتفيذها على إجراءات التنفيذ وعلى مزاولة سلطات الضبط القضائى المخولة لهم بموجبها. ء) غياب التظظيم القانونى لمزاولة مهنة البيئين حيث يزاول أعمال ودراسات التقييم البيئى للمنشآت المقامة بالمنطقة محل الدراسة ووضع الخطط البيئية لها وتوفيق أوضاعها أثخاص غير متخصصين مما ينتج عنه خلل فى إجراء هذه الأعمال وبالتالى تعرض أصحاب المنشآت لأضرار نتيجة لذلك، الأمر الذى يتطلب وضع تنظيم قانونى لمزاولة

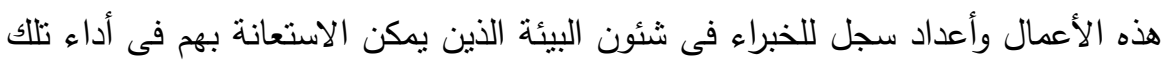

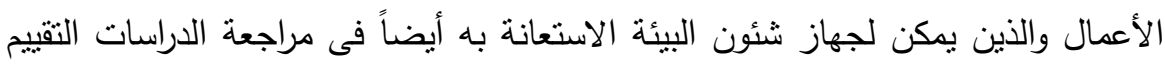
البيئى للمشروعات الجديدة أو التوسعات أو التجديدات فى المشروعات الائعانة بهات القائمة.

\section{المتوصياهت}

() ضرورة تفعيل القوانين والقواعد والتشريعات المنظمة للحفاظ على الطاقة الأستبعابية باستخدام آليات قابلة للتنفيذ والتطوير والتقييم والتعديل.

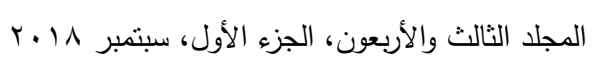


r) العمل على انشاء من خلال بنك متكامل للمعلومات البيئية وشبكات منطورة للرصد البيئى. ولا شك أن توافر هذه المعلومات لاى صانعى القرار والمسئولين عن البيئة يجعل الدولة

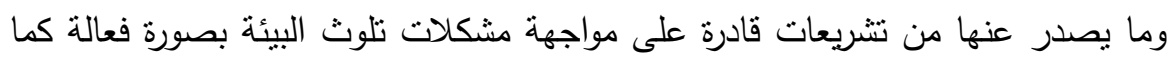

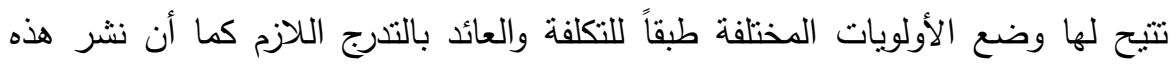
المعلومات يتيح تتقيفاً بيئياً للمجمع ويرفع الوعى البيئى لدى الجماهير حيث يطلع أفراد

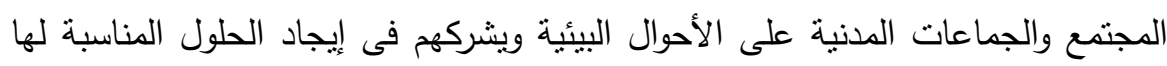
بما يتتاسب والظروف الاقتصادية والاجتماعية القائمة.

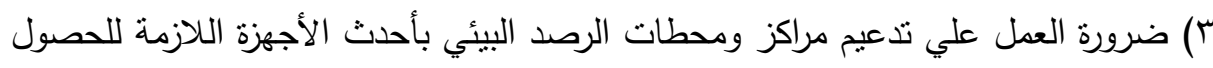
علي حالة للطاقه الأستيعابية وكافة القياسات البيئية المختلفة للبحر الأحمر بصفة داهية دورية ومنتظمة تساعد علي معرفة الموقف الحالي في كل وقت وموقع. ومعالجة أي مشكلة بيئية تتشأ في تلك المناطق فور ظهورها ومعرفة الأسباب المؤدية ها علاجها بصورة حازمة وسريعة.

ء) قيام الجهات الإعلامية والسياحية بتوضيح الصورة الحقيقية لموقف للطاقه الأستبعابيه وما تعانيه من مشكلات بيئية ومدى نجاح أو أخفاق جهة الأدارة في علاج تلك المشكلات الاته

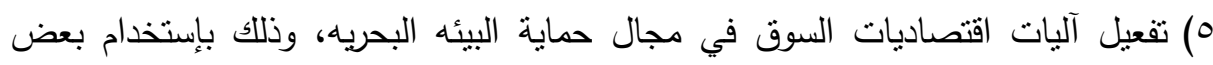

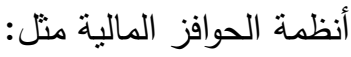
- إعفاءات جمركية لمعدات ومكافحة النلوث والتكنولوجيا صديقة البيئة. - مزايات ضريبية للمشروعات والأنشطة المقامة غلى ساحل البحر الأحمر و التي تنخل البعد البيئي في تصميمها. 7) إنشاء صندوق خاص بالبيئة البحرية تؤول إليه أموال التعويضات والغرامات الناتجة عن مخالفات الطاقه الأستيعابيه تخصص أمواله في مشروعات حماية البيئة البحرية وتحسينها سواء كانت مشروعات بحثية أو تتفيذية، ويصرف من أموال هذا الصندوق كمكافآت المرشدين والضابطين لنللك الجرائم و تكاليف إزالة التلوث البحري.

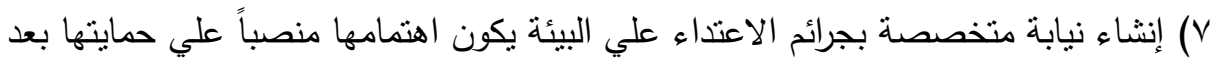
تميزها بنظام قانوني منكامل. 
^) انشاء محاكم متخصصة بنظر الجرائم البيئية لسرعة الفصل فيها فضلاً عن نتظيم دورات تدريبية متخصصة في جرائم البيئة لاعضاء النيابة العامة والقضاة للوقوف علي مدى لئه

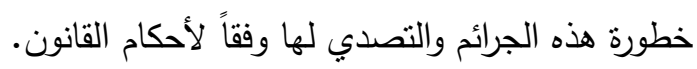

9) عقد لقاءات (جلسات - ندوات - مؤتمرات...الخ) بين رجال السلطات الثلاثة (قضائية تتفيذية - تشريعية) فى حضور جهة علمية فنية لمحاولة تقريب وجهات النظر بينهم للوقوف على نقاط الضعف فى المواجهة.

\section{المرالئar}

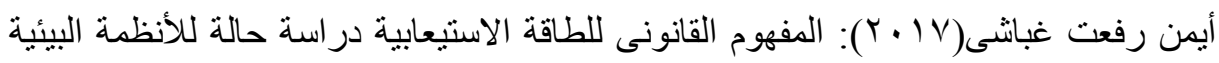

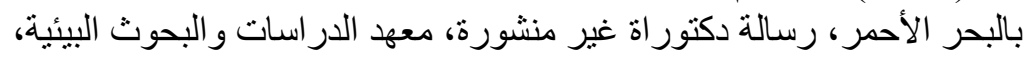
جامعة عين شمس الأسرس

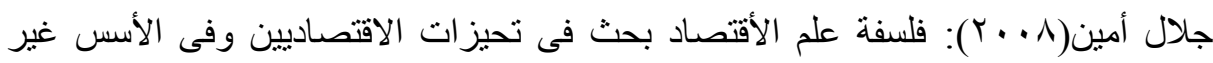

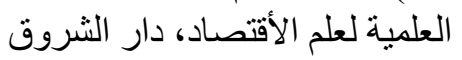

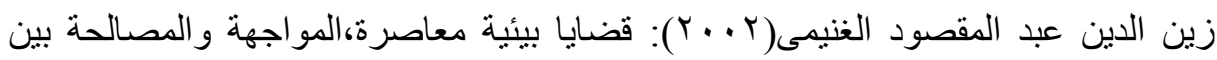
الإنسان وبيئته، الإسكندرية، منشأة المعارف

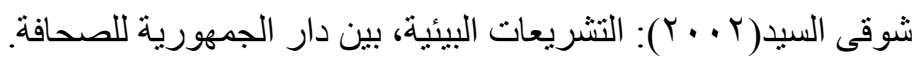

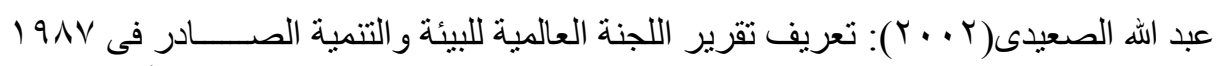

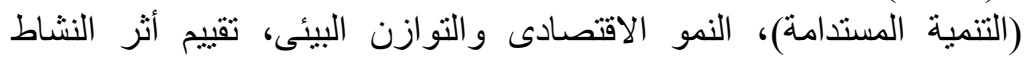
الإقتصادى على عناصر النظام البيئى، دار النهضئة العربية

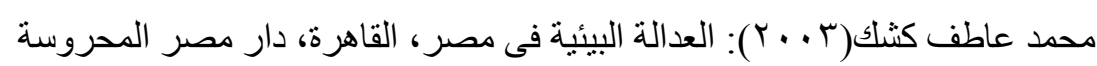

Conservation International and World Resource Institute (2008): Economic Values of Corel Reefs, Mangroves, and Sea grasses: A Global Compilation. Center for Applied Biodiversity Science, Conservation International, Arlington, VA, USA.

Report for the Red Sea and Gulf of Aden (2006): Environment Regional Organization for the Conservation Red sea and Gulf of Aden.

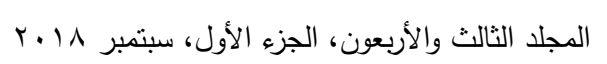




\title{
THE LEGAL CONCEPT OF CARRYING CAPACITY CASE STUDY RED SEA ENVIRONMENTAL ECO SYSTEM
}

\author{
Ghobashi, A. R. ${ }^{(1)}$; Abdel Wahed, F. Z. ${ }^{(2)}$ and Helal, A. M.
}

[20]

1) Egyptian Ministry of Interior 2) Faculty of Law, Ain Shams University 3) Faculty of Science, Azhar University

\begin{abstract}
The aim of the study to know the legislations and the administrative regulations related to marine environmental protection in the area of the study as a part of the environmental legislations in Egypt using the descriptive and statistic curricula of the random specimen of diving centers workers in the Red Sea reservoirs and those implementing the legislations and laws. A questionnaire has been designed including statements measuring the specimen's tendency, which included fifty four people.

The study concluded that there are defects in current legislations in regards to marine environmental carrying capacity sustainability, due to not accurately specifying the violation, the lack of clear and updated environmental information besides the lack of environmental awareness of the workers managing marine environmental offices in the area of study which in turn increases the problem. This is in addition to the need for advanced networks for environmental monitoring and an integrated bank for environmental information. Decision makers will then have a clear vision in determining the causes of marine environmental degradation and will set the means for combating them using the set of applicable legislations with the support of all related parties, whether the civil, executive or judicial.
\end{abstract}

